\title{
PREPARING INMATES FOR COMMUNITY RE-ENTRY: AN EMPLOYMENT PREPARATION INTERVENTION
}

\author{
by \\ ERICA LEIGH MEDLOCK
}

\begin{abstract}
A DISSERTATION
Presented to the Department of Counseling Psychology and Human Services and the Graduate School of the University of Oregon in partial fulfillment of the requirements for the degree of Doctor of Philosophy
\end{abstract}

September 2009 


\title{
University of Oregon Graduate School
}

\section{Confirmation of Approval and Acceptance of Dissertation prepared by:}

\author{
Erica Medlock
}

Title:

"Preparing inmates for community re-entry: An employment preparation intervention"

This dissertation has been accepted and approved in partial fulfillment of the requirements for the Doctor of Philosophy degree in the Department of Counseling Psychology and Human Services by:

Linda Forrest, Chairperson, Counseling Psychology and Human Services

Krista Chronister, Member, Counseling Psychology and Human Services

Deanne Unruh, Member, Special Education and Clinical Sciences

Robert O Brien, Outside Member, Sociology

and Richard Linton, Vice President for Research and Graduate Studies/Dean of the Graduate School for the University of Oregon.

September 5, 2009

Original approval signatures are on file with the Graduate School and the University of Oregon Libraries. 
An Abstract of the Dissertation of

Erica Leigh Medlock for the degree of Doctor of Philosophy in the Department of Counseling Psychology and Human Services

to be taken

September 2009

Title: PREPARING INMATES FOR COMMUNITY RE-ENTRY: AN EMPLOYMENT

PREPARATION INTERVENTION

Approved:

Dr. Linda Forrest

The purpose of this dissertation study was to adapt, deliver, and experimentally test the effectiveness of a research-based, employment-focused group counseling intervention (OPTIONS) that was designed to improve male inmates' ability to secure employment upon release from prison. The intervention curriculum and study were modeled after similar interventions with battered (Chronister \& McWhirter, 2006) and incarcerated women (Chartrand \& Rose, 1996). The OPTIONS program was grounded in Social Cognitive Career Theory (SCCT; Lent, Brown, \& Hackett, 1994, 2000) and comprised of all critical intervention components identified as contributing to positive career intervention outcomes (Brown \& Krane, 2000). In addition, the OPTIONS intervention consisted of 5 weekly group sessions, which lasted 120 minutes, and each group was comprised of 6-7 male inmates. The intervention focused on various aspects of the job preparation process such as identifying necessary skills, obtaining information 
about different types of jobs, practicing for job interviews, and learning how to utilize social support. Study participants included $77(\mathrm{n}=38$ treatment, $\mathrm{n}=39$ control $)$ adult male inmates housed at the Oregon Department of Corrections medium security release facility, the Oregon State Correctional Institute (OSCI) in Salem, OR. This study utilized a randomized block design, with between subjects and within subjects measurements at pretest, posttest, and one month follow-up. Participants were blocked based upon age and release date, and then randomly assigned to a wait-list treatment as usual control group or the OPTIONS treatment intervention group. Outcomes measured were job search selfefficacy (Career Search Self-Efficacy Scale, Solberg, Good, \& Nord, 1994), perceived problem solving ability (Problem Solving Inventory, Heppner, 1988), and hopefulness (Hope Scale, Snyder et al., 1991). Data were analyzed using 2 (experimental group) x 2 (time) analyses of variance (ANOVAs). Results indicated that participants in the OPTIONS treatment intervention had higher career-search self-efficacy, problem solving, and hopefulness scores at posttest and follow-up than participants in the treatment as usual control group. This dissertation study was the first time a manualized, theory based employment preparation treatment intervention was adapted specifically for inmates preparing to release back to the community. 


\section{CURRICULUM VITAE}

NAME OF AUTHOR: Erica Leigh Medlock

PLACE OF BIRTH: Zanesville, Ohio

DATE OF BIRTH: April 11, 1979

\section{GRADUATE AND UNDERGRADUATE SCHOOLS ATTENDED:}

University of Oregon

Michigan State University

Ohio University

Denison University

\section{DEGREES AWARDED:}

Doctor of Philosophy in Counseling Psychology, 2009, University of Oregon Master of Arts in Counseling, 2002, Michigan State University

Bachelor of Science in Interpersonal Communication, 2000, Ohio University

\section{AREAS OF SPECIAL INTEREST:}

Corrections

Crisis Intervention 
PROFESSIONAL EXPERIENCE:

Predoctoral Intern, Federal Correctional Institute, Fort Worth, Texas, 2008-2009

Therapist, Sacred Heart Medical Center Johnson Unit, Eugene, Oregon, 20072008

Director, University of Oregon Crisis Center, Eugene, Oregon, 2005-2007

Counselor, Lane Community College Counseling Center, Eugene, Oregon, 2004-2007

Intern, Oregon State Correctional Institute, Salem, Oregon, 2005-2006

Intern, Lane Community College Counseling Center, Eugene, Oregon, 2003-2004

\section{GRANTS, AWARDS AND HONORS:}

Outstanding Student Poster, Preparing Inmates for Community Re-Entry: An Employment Preparation Intervention, Mental Health in Corrections Consortium, 2008

Graduate Research Fellowship, Preparing Inmates for Community Re-Entry: An Employment Preparation Intervention, University of Oregon, 2008

Certificate of Merit, American Psychological Association Division 18:

Psychologists in Public Service, 2006

Fighting Funds Fellowship, Graduate School, University of Oregon, 2002 


\section{ACKNOWLEDGMENTS}

I wish to express sincere appreciation to Dr. Linda Forrest for her support, guidance, and assistance throughout my graduate study. Second, I would like to thank Dr. Krista Chronister for her enthusiasm, dedication, and commitment to the revision of the OPTIONS curriculum. Third, I would like to thank Dr. Paul Bellatty, Director of Research for the Oregon Department of Corrections, as well as the administration and staff at Oregon State Correctional Institute for their endorsement of this dissertation study. Fourth, I extend sincere gratitude and appreciation to Gina Prendes-Lintel Furr and Courtney Jellar, graduate students in Counseling Psychology, for their commitment and devotion to facilitating the OPTIONS program. Fifth, I would like to thank the inmates at Oregon State Correctional Institute for participating in this dissertation study and for their commitment to ensuring inmates continue to benefit from the OPTIONS program in the future. Finally, I would like to thank my husband Brodie and my children Conner and Avery for their undying love and devotion as I spent many hours working on this project. 
For Conner and Avery 


\section{TABLE OF CONTENTS}

I. LITERATURE REVIEW $\ldots \ldots \ldots \ldots \ldots \ldots \ldots \ldots \ldots \ldots \ldots \ldots$

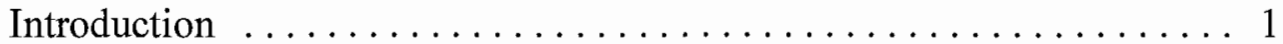

Obstacles to Re-Entry ......................... 4

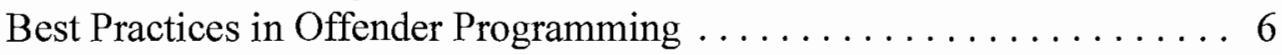

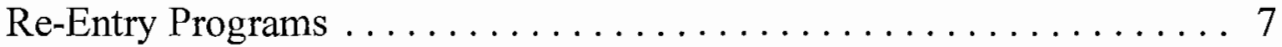

Social Cognitive Career Theory . . . . . . . . . . . . . . . . . 15

Research Questions and Hypotheses . . . . . . . . . . . . . . . 19

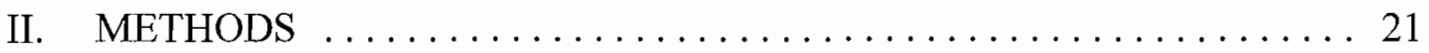

Research Design ........................... 21

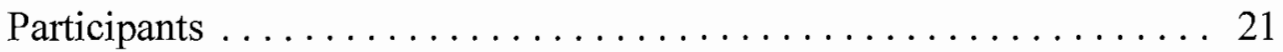

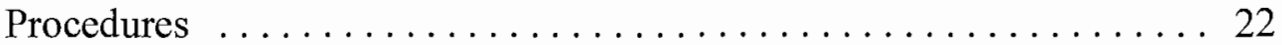

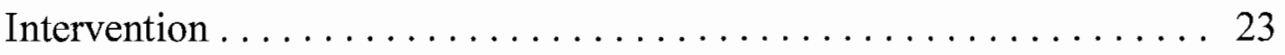

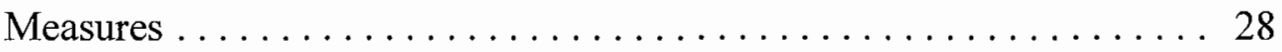

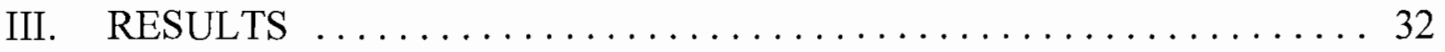

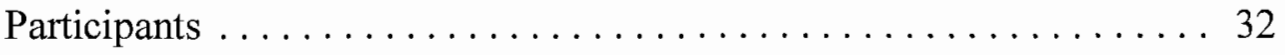

Preliminary Analyses and Results $\ldots \ldots \ldots \ldots \ldots \ldots \ldots$

IV. DISCUSSION $\ldots \ldots \ldots \ldots \ldots \ldots \ldots \ldots \ldots \ldots \ldots \ldots \ldots \ldots \ldots \ldots$

Career-Search Self-Efficacy $\ldots \ldots \ldots \ldots \ldots \ldots \ldots \ldots \ldots \ldots . \ldots \ldots$

Perceived Problem-Solving Ability . . . . . . . . . . . . . . . 44

Hopefulness . . . . . . . . . . . . . . . . . . . 48

Additional Treatment Considerations . . . . . . . . . . . . . 50

Contextual Factors Impacting Study Procedures . . . . . . . . . . . . . 52 


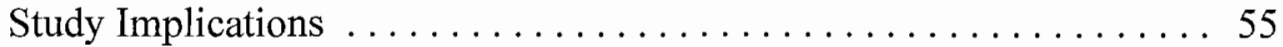

Inmate Feedback . . . . . . . . . . . . . . . . . . 58

Feedback From Group Facilitators . . . . . . . . . . . . . . . . 60

Strengths and Limitations . . . . . . . . . . . . . . . . . . 61

Recommendations for Future Research . . . . . . . . . . . . . . 64

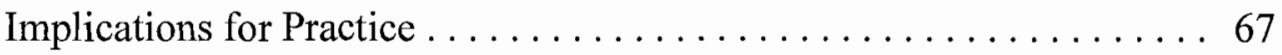

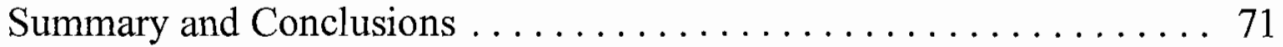

\section{APPENDICES}

A. DEMOGRAPHIC QUESTIONNAIRE $\ldots \ldots \ldots \ldots \ldots \ldots \ldots$

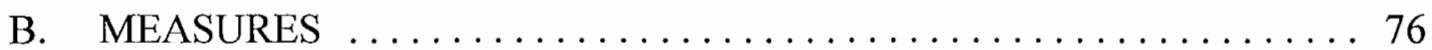

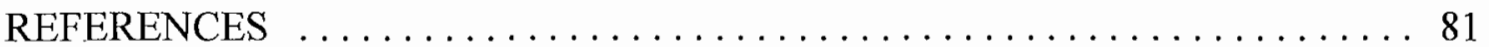




\section{LIST OF TABLES}

Table

1. Distinguishing Characteristics of ACCESS and OPTIONS Curricula .... 26

2. Reliability Coefficients for the Present Sample . . . . . . . . . . . . . . . 29

3. Means and Standard Deviations for Continuous Demographic

Variables ............................. 33

4. Frequencies and Percentages for Categorical Demographic

Variables . . . . . . . . . . . . . . . . . . . . . . . . . 33

5. Significance of Differences Between Treatment and Control Groups

at Pretest, Posttest, and Follow-Up . . . . . . . . . . . . . . . . . 34

6. Means, Standard Deviations, and Correlations for All Measures at Pretest .............................. 35

7. Means and Standard Deviations for Dependent Measures Across

Time ............................... 38 


\section{CHAPTER I \\ LITERATURE REVIEW}

\section{Introduction}

In the United States over 2.3 million people are incarcerated in prison or jail, with an additional 5 million on probation or parole. It is estimated that $95 \%$ of these inmates will return to the community at some point (Bureau of Justice Statistics, 2004). Each year approximately 600,000 inmates are released into communities across the country (Bureau of Justice Statistics, 2004; Marbley \& Ferguson, 2005; Petersilia, 2004). The prison population saw a growth of over $700 \%$ from $1970-2005$ and is estimated to increase by an additional 13\% between 2007 and 2011 (Public Safety Performance Project, 2007). This growth in prison population will also increase the number of individuals released from prison into communities each year.

Finding employment is one of the greatest barriers to successful reintegration for ex-offenders (Harrison \& Schehr, 2004). If ex-offenders are unable to secure employment, they are more likely to return to previous criminal behaviors and substance abuse (Filella-Guiu \& Blanch-Plana, 2002; Leukefeld et al., 2003; Rahill-Beuler \& Trait Kretzer, 1997; Uggen, 1999; Visher, Winterfield, \& Coggeshall, 2005). Many scholars have found a positive relationship between joblessness and criminal activity, especially 
in impoverished areas (Bloom, 2006; Chartrand \& Rose, 1996; Filella-Guiu \& BlanchPlana, 2002; Harrison \& Schehr, 2004). Ex-offenders must deal with stigma attached to a criminal record, and limitations on types of employment they can obtain (Harrison \& Schehr, 2004; Visher et al., 2005).

Unemployment is a stressful life event that can lead to financial difficulties, depression, anxiety, somatic symptoms, and increased substance use (Wanberg, Kanfer, \& Rotundo, 1999). Add to unemployment stress the additional re-entry stressors of finding housing, re-establishing contact and relationships with friends and family members, and the rigors of postprison supervision, and the ex-offender is at high risk of returning to criminal behavior.

According to meta-analyses of ex-offender employment programs and recidivism, stable employment is one of the strongest predictors of postrelease success (Visher et al., 2005). Numerous studies have indicated a significant link between successful treatment of drug and alcohol dependence and employment for ex-offenders (Leukefeld et al., 2003; Platt, 1995; Wolkstein \& Spiller, 1998). Employed individuals are more likely to report healthy social and professional networks, and an increase in self-esteem and self-worth (Bloom, 2006; Leukefeld et al., 2003).

For the purpose of this study, I conducted a comprehensive literature review using Psych Info, Psych Lit and Sociological Abstracts databases. In the search, I included books, book chapters and articles dating from 1965 to 2007. I entered keywords and phrases such as re-entry, recidivism, ex-offender employment, inmate 
employment programs and various combinations and alternate terms such as offender, career, job, convict. I also searched the internet using Google to find recently published congressional documents and reports related to re-entry and recidivism. A multitude of literature exists that highlights the difficulty faced by ex-offenders reintegrating into society. Limited studies exist examining the effects of comprehensive employment preparation programs on the employment success of ex-offenders. Several studies exist utilizing a social cognitive career theory-based intervention with at-risk populations (Chartrand \& Rose, 1996; Chronister \& McWhirter, 2006). To date there are no published empirical studies that measure the efficacy of a theory-based career intervention with male ex-offenders.

The purpose of this dissertation study was to adapt, deliver, and experimentally test the effectiveness of a research-based employment counseling group intervention that was designed to improve male inmates' ability to secure employment upon release. The ultimate goal was to assist inmates in developing the necessary skills to find and maintain employment. In this study, I adapted, delivered and tested a job-preparation group intervention (OPTIONS) based on Lent, Brown, and Hackett's (1994) Social Cognitive Career Theory. The design of the study and the OPTIONS curriculum were modeled after similar interventions with battered (Chronister \& McWhirter, 2006) and incarcerated women (Chartrand \& Rose, 1996).

This chapter provides a comprehensive review of the literature regarding ex-offenders and societal reintegration, employment issues, programs designed to 
facilitate effective re-entry, and career development theory. The organization of this chapter is as follows: First, I describe obstacles faced by ex-offenders as they transition from prison to free society with a specific focus on employment issues. Second, I describe best practices in offender programming. Third, I discuss several major studies examining interventions specifically designed to alleviate re-entry difficulties with a specific focus on employment-focused programs for ex-offenders. Fourth, I discuss Social Cognitive Career theory. Finally, I conclude with research questions and hypotheses.

\section{Obstacles to Re-Entry}

Upon release from prison, ex-offenders usually receive somewhere between $\$ 75$ and $\$ 100$ if being released from state departments of corrections, and approximately $\$ 100-\$ 500$ if released from the Federal Bureau of Prisons (Harrison \& Schehr, 2004). Unless an ex-offender has lined up employment, is able to secure employment within a few days, or has a financially supportive partner or family, the ex-offender is left with little to no money for food, clothing, transportation, and housing. In addition, many ex-offenders are required to travel to and from appointments with parole officers, and often have to pay fees and fines related to parole (Petersilia, 2004).

Ex-offenders entering the labor market are at a significant disadvantage. Due to criminal activity and incarceration, ex-offenders often have little to no prior work experience, are undereducated, and frequently have cognitive difficulties (Bloom, 2006; 
Chartrand \& Rose, 1996). In addition many ex-offenders struggle with substance abuse and mental or physical health issues (Bloom, 2006; Holzer, Raphael, \& Stoll, 2003; Seiter \& Kadela, 2003; Vernick \& Reardon, 2001). Many ex-offenders are able to find employment eventually if they search long enough (Holzer et al., 2003). However, these jobs tend to pay minimum wage, have few if any benefits, and little opportunity for advancement (Holzer et al., 2003). This creates little incentive for ex-offenders to maintain such jobs, and can be a motivation to return to illegal activity to make a living wage; therefore, sustainable wages are a vital component to preventing recidivism (Harrison \& Schehr, 2004).

Ex-offenders must deal with stigma attached to a criminal record, and limitations on types of employment they can obtain depending upon the crime for which they were incarcerated (Harrison \& Schehr, 2004). Once an individual has been convicted of a felony, certain jobs are legally closed to them. Many jobs in security, the healthcare industry, and the financial sector, or requiring contact with children are no longer open to those with felony convictions (Bushway, 1998; Holzer et al., 2003). State and federal laws also place restrictions on ex-offenders from obtaining professional licensure in a broad range of occupations, including barber, plumber, and electrician, jobs for which many inmates may be qualified. Race, gender, and geographical location are other factors that limit job prospects for many ex-offenders. Studies have shown African American men are much less likely than European American men with equal or lesser qualifications to receive job offers (Holzer et al., 2003). This applies to ex-offenders as 
well. African American ex-offenders are less likely to receive job offers than European American ex-offenders despite equal to or greater qualifications. Ex-offenders returning to inner city or rural areas face limited job availabilities, as jobs are scarce in these areas to begin with (Bloom, 2006).

Studies indicate many employers are less willing to hire an ex-offender than any other disadvantaged group. For example, in a study by Holzer et al. (2003), over $90 \%$ of employers surveyed were willing to hire a welfare recipient, whereas only $40 \%$ were willing to hire an ex-offender.

Unemployment statistics for ex-offenders are hard to document and policymakers are looking at ways to track such data reliably. Bloom (2006) reported results from a recent survey of male prisoners returning to Chicago in which only $44 \%$ reported working for at least a week in the first 4-8 months out of prison. The majority of that $44 \%$ worked only part time. A similar survey in Baltimore reported $64 \%$ of men worked within 6 months after their release, but again, the work was often part time and sporadic (Bloom, 2006). An analysis of unemployment data in Florida indicated $40 \%$ of ex-offenders were working in an unemployment-insurance-covered job one year postrelease.

\section{Best Practices in Offender Programming}

A great deal of literature exists that supports the use of cognitive and cognitive behavioral techniques with incarcerated populations (Andrews et al., 1990; Bourgon, \& 
Armstrong, 2005; Gendreau, 1995, 1996; Inciardi, Martin, \& Butzin, 2004; Wilson, Bouffard, \& MacKenzie, 2005). Researchers have found many inmates experience cognitive deficits, or deficits in problem-solving ability and interpersonal skills (Bloom, 2006; Chartrand \& Rose, 1996; Ross \& Fabiano, 1980; Ross, Fabiano, \& Ewles, 1988). Scholars have identified a number of key components to effective re-entry programs for ex-offenders (Andrews et al., 1990; Gendreau, 1995, 1996). Effective programs are cognitive behavioral in nature and include modeling of prosocial skills and behaviors (Andrews et al.; Gendreau; Gendreau). Programs adhere to the responsivity principle in that they teach new prosocial skills to the ex-offender (Bourgon, \& Armstrong; Gendreau; Gendreau). Finally, effective programs target the criminogenic needs of the ex-offender. Criminogenic needs are defined as those that when changed alter the probability of recidivism (Andrews et al.; Bourgon \& Armstrong; Gendreau; Gendreau). Examples of criminogenic needs include antisocial attitudes and behaviors toward authority, criminal companions, illegal leisure activities, deviant peers, substance abuse, and unemployment (Andrews et al.; Bourgon \& Armstrong; Gendreau).

\section{$\underline{\text { Re-Entry Programs }}$}

A quantitative synthesis by Wilson et al. (2005) on group-oriented cognitive behavioral interventions for inmates showed a positive effect size in terms of participants' reductions in criminal behaviors $(0.32, p<.001)$. Common components of 
effective cognitive behavioral interventions include a strong foundation in cognitive behavioral theory and "an emphasis on broad human change, but with a clear emphasis on demonstrable, behavioral outcomes achieved primarily through changes in the way an individual perceives, reflects upon, and, in general, thinks about their life circumstances" (Wilson et al., 2005, p. 173). The meta-analysis had several strengths. For example, the authors searched multiple databases, using extensive variations of the terms cognitive and cognitive behavioral crossed with terms such as offender, inmate, criminal, etc., and utilized rigorous inclusion criteria. The search yielded 31 documents covering results from 20 separate studies. The analysis included both published (55\%) and unpublished (45\%) documents and reports, thus decreasing the likelihood of publication bias. Only $20 \%(n=4)$ of the studies included in this meta-analysis were randomized experiments. The remainder of the studies were either high quality quasiexperimental $(n=7)$ or low quality quasi-experimental $(n=9)$. The overall findings from this study (Wilson et al., 2005) support the use of cognitive and cognitive behavioral interventions with incarcerated individuals, thus providing support for the curriculum for my study, which is based on social cognitive career theory.

Another example of a successful cognitive behavioral intervention is that of Inciardi et al. (2004). The authors evaluated 5-year outcomes of a cognitive behavioral, therapeutic community drug treatment program for 690 individuals in the Delaware correctional system. The therapeutic drug treatment program focused on the development of prosocial values, the importance of supportive social networks, and 
personal choice and responsibility. In the final stages of the intervention, participants prepared for employment by engaging in mock interviews, learning about how to do job searches, and finding ways to gain further education and/or vocational training. A major strength of this study is the utilization of a no-treatment control group design. A major weakness of the study was participants who had completed some form of drug treatment while incarcerated were given priority for receiving the treatment component of the intervention. It is unclear how participants with prior drug treatment faired as compared to participants with no prior drug treatment. Results indicated participants in the treatment condition had a $70 \%$ reduction in the odds of a new arrest at 42 -month postbaseline. Overall, participants in the treatment condition were three times more likely to remain drug free than the control group.

Seiter and Kadela (2003) used the Maryland Scale of Scientific Methods (MSSM) to identify re-entry programs that were effective. A strength of this study was that it examined studies that were experimental or quasi-experimental. Types of programs included (a) vocational and work training, (b) sex offender treatment, (c) drug and alcohol treatment, (d) education programs, (e) halfway houses, and (f) prison prerelease programs. Based on the results of their analysis, the authors concluded vocational and work programs are effective in reducing recidivism and improving employability of offenders. Although the results of the Seiter and Kadela analysis discovered many programs that worked to help ease re-entry, a criticism of their study is only a small number of programs were studied. In addition, limited longitudinal data 
have been collected; therefore, the effectiveness of these programs over time is still unknown. This analysis supports the utilization of a job-preparation program in corrections and validates the need for empirically supported programs in corrections.

A great deal of literature exists supporting the need for employment-focused programs in corrections and postrelease. A large quantity of employment-focused programs exist; however, few have been empirically studied. In addition, few if any programs focus on interpersonal issues, choice and personal agency.

An article by Vernick and Reardon (2001) highlighted the need for additional career-related services for ex-offenders. Their review of the literature on career development in corrections noted the majority of employment-focused programs in corrections focused specifically on job skills but did not attend to more comprehensive issues associated with career development. The authors emphasized the need for programs that allow ex-offenders to develop career plans based upon their interests, values, skills and options in the work force, and the need for empirical research on such programs (Vernick \& Reardon, 2001). Vernick and Reardon suggested programs include training on how to get along with co-workers, how to tolerate and sustain less than desirable positions long enough to get promoted, how to acquire further job training, and how to utilize both formal and informal support networks.

One of the most frequently referred to analyses in recent literature of employment-focused programs for ex-offenders is a meta-analysis by Visher et al. (2005). The authors included only studies that used random assignment to treatment and 
control. To be included in the analysis the treatment program had to include a job training or placement component and at least some of the treatment had to take place outside of a secure, custodial setting (i.e., not in prison or jail). The results yielded eight studies meeting the criteria of random assignment to treatment or control group. The mean effects size is 0.03 , which is not statistically significant. The authors state "this finding indicates that, on average, the employment interventions examined did not reduce arrest among the treatment group subjects by more than the amount expected by chance" (p. 306). The authors concluded that the effectiveness of these types of programs is not yet known, as few programs have been empirically validated. Strengths include the extensive search of a variety of databases, and the authors' solicitation of unpublished works by contacting many known researchers in the field of ex-offender employment. Several weaknesses are observed in this review of eight studies. Not all participants were ex-offenders, and the majority of the programs evaluated were in effect from the 1970s and 1980s and therefore may not be as applicable to today's economic and employment environment. In addition, the criminal justice system and number of individuals involved in the criminal justice system looks drastically different today than it did 20 years ago. The findings of this study further support my claim of a need for current evaluation and research on job preparation and employment programs in correctional settings.

Several authors (Bloom, 2006; Seiter \& Kadela, 2003; Unwin, Mayers, \& Wilt, 1999) mentioned the Ohio Department of Rehabilitation and Corrections' Offender Job 
Linkage Program. This program consists of basic skills for community functioning such as communication, resumé preparation, job-search assistance and job-interview preparation. The program was designed for inmates within 6 months of release. Authors speculated on the effectiveness of this program; however, it has never been officially evaluated. The Ohio model is promising in that it incorporates a variety of necessary skills, which are probably associated with successful re-entry. If these skills were studied empirically, they would likely provide important contributions to the literature on effective employment programs for ex-offenders.

A study conducted in Spain by Filella-Guiu and Blanch-Plana (2002) showed positive effects of an employment-guidance program on the employability of ex-offenders. The objectives were to (a) improve individual competence in job searching, (b) facilitate the acquisition of useful job-search knowledge and skills, and (c) increase professional self-esteem (Filella-Guiu \& Blanch-Plana, 2002). The employment program incorporated (a) job market analysis and professional needs and competences, (b) where to search for a job, (c) practical elements of the job-search process, and (d) workers' rights and duties. The sample consisted of 256 offenders participating in employment-focused courses in the prison during a 3-year period. Participants were randomly assigned to the intervention group or "treatment as usual" control group. The program was delivered in 2-hour sessions; however, the number of sessions and the duration of the program were unclear. The study employed a pre-post control group design. Participants were evaluated using interviews and questionnaires 
measuring knowledge and skills related to employment and self-esteem relative to their ability to be successful in employment. The specific measures were not named, nor were they included in the article. Thus, the psychometric properties of the measures and any potential limitations are unknown. The mean scores at pre- and immediately postintervention were reported. The treatment group showed a significant increase in their mean scores in both knowledge and skills related to the job-search process and professional self-esteem at posttest. In addition, the participants were measured 6 months postrelease and were found to have an employment rate of $48 \%$ versus the control group employment rate of $23 \%$. Although the findings are significant and indicated the program was successful in attaining its objectives, the results may not be directly applicable to inmates in the United States, as the justice system, economy, and employment barriers facing ex-offenders could potentially be quite different in Spain. These factors were not addressed in the article, and therefore the results should be generalized to U.S. prison populations with caution. In addition, it is unclear what measures were used in this study and if they were empirically supported.

Leukefeld et al. (2003) created an employment intervention for drug court participants. The goals of the intervention were to help participants gain, maintain, and upgrade employment status. The intervention included resumé writing, interviewing, resolving conflicts at work, setting goals, problem solving, and techniques to facilitate job advancement. This study utilized pretest/posttest experimental design with random assignment to the employment intervention group or "treatment as usual" control group. 
Participants were 500 individuals participating in Drug Court in two major midwestern cities. At pretest, all participants underwent an extensive interview. The interview covered current and previous employment, levels of current and past substance abuse, criminal justice involvement, health and mental health, and HIV risk behavior. No empirically validated measures were used in this study. Anecdotal data reported in the article stated participants felt more confidence in terms of searching for a job, and dealing with barriers to employment as identified by their follow-up interviews. The strengths of the study include a large number of participants $(n=500)$, a treatment-asusual comparison design and long-term follow-up. One limitation of the study is the lack of use of empirically validated measures. In addition, the group intervention, although theory based, was not manualized, thereby creating a threat to validity. This study is an example of the need for rigorous empirical validation of interventions.

With regard to findings, Visher et al. (2005), in a meta-analysis of eight studies, found no difference in rates of recidivism between treatment groups receiving employment interventions and control groups. The Ohio Offender Job Linkage program sounds promising, but has not yet been empirically validated. Treatment participants in the study by Filella-Guiu and Blanch-Plana (2002) showed significant increases in knowledge about the world of work, skills, and self-esteem, and had higher levels of employment in comparison to the control group. However, the exact measures used in this study are unknown and the study took place outside of the United States, creating difficulty in terms of comparability to U.S. offenders. The Leukefeld et al. (2003) study 
indicated anecdotal evidence showed an increase in self-confidence related to finding employment and navigating employment barriers; however, no empirical measures were used. According to this review of the literature, some employment interventions appear to work, and some do not. However, due to significant design flaws such as lack of random assignment and lack of empirically validated measures, further research is needed to determine the efficacy of theory-based employment interventions for inmates. In summary, the limitations of the studies reviewed support a need for further empirical validation of employment-focused interventions for ex-offenders in the United States.

\section{$\underline{\text { Social Cognitive Career Theory }}$}

Social Cognitive Career Theory (SCCT) applies Bandura's (1986) social cognitive theory to the areas of vocational and educational interest development (Lent, Brown, \& Hackett, 1994). SCCT emphasizes the influence between person and environment on the development of vocational goals, interests, and abilities. According to SCCT, three key variables are thought to enable individuals to exercise personal control of their vocational and educational pursuits: self-efficacy, outcome expectations, and goals. Self-efficacy is "people's judgments of their capabilities to organize and execute courses of action required to attain designated types of performance" (Bandura, 1986, p. 391, as cited in Lent, Brown, \& Hackett, 1994, p. 83). Outcome expectations are defined as "personal beliefs about probable response outcomes" (Lent, Brown, \& Hackett, 1994, p. 83). Goals help organize behavior and execute certain actions and 
behaviors which one can sustain over long periods of time (Lent, Brown, \& Hackett, 1994).

SCCT has been utilized to describe and assess the career development of members of marginalized groups, and has been found to be empirically supported with diverse populations (Chartrand \& Rose, 1996; Chronister \& McWhirter, 2003; Hackett \& Byars, 1996; Morrow, Gore, \& Campbell, 1996). SCCT"s attention to environmental factors (e.g., poverty, oppression, discrimination), and interactions among the characteristics of the individual and his/her multiple environmental contexts, situate the theory as an ideal theoretical foundation for developing a job-preparation intervention for prerelease inmates.

Empirical literature supports brief job choice interventions (Brown \& Krane, 2000). As such the program consisted of five sessions facilitated by a trained leader. The intervention had five components: written exercises, information about the world of work, individualized interpretation of assessments and feedback, strategies for finding employment support, and role modeling. These five components were highlighted as key components that tend to dramatically improve effectiveness of career choice interventions and are consistent with best practices in ex-offender programming (Andrews et al., 1990; Gendreau, 1995, 1996). For this study, the goals of the career intervention included increasing knowledge and awareness of career limitations due to criminal history, career goal planning, knowledge and utilization of community 
resources and supports, awareness and development of career-search skills, and exploration of career interests.

Learning how to navigate multiple environments while dealing with the stressors associated with re-entry can be overwhelming to ex-offenders. Several components of the employment-preparation intervention addressed these needs and empowered the individual to exert personal agency in decision-making and action. The two components are critical consciousness and empowerment theory. First I will describe the concept of critical consciousness and then discuss empowerment theory and how it was applied in the intervention.

\section{Critical Consciousness}

Critical consciousness is a concept developed by Brazilian educator Paulo Freire (1970). Freire defined critical consciousness as "learning to perceive social, political, and economic contradictions, and to take action against the oppressive elements of reality" (p. 19). Diemer and Blustein (2006) defined critical consciousness as "the capacity to recognize and overcome sociopolitical barriers" (p. 220). Chronister and McWhirter (2006) described critical consciousness as "becoming more aware of self (identity), others (context), and the relation of self to others (power dynamics) and accordingly gaining a critical understanding of control and responsibility in one's life situations" (p. 153). 
Six components were utilized in the intervention to enhance critical consciousness: (a) dialogue (exchange of and reflection upon ideas); (b) group identification (increase of social support); (c) problem posing (reflecting upon beliefs and realities held by individuals); (d) identifying contradictions (naming discrepancies); (e) power analysis (examining how power is used and distributed; McWhirter, 1994); and (f) critical self-reflection (increasing awareness of power, privilege, and ability to act; Chronister \& McWhirter, 2006).

\section{Empowerment}

The topics discussed in the intervention were intense in nature and may have felt overwhelming to some individuals. Furthermore, it was important in discussing the barriers faced by ex-offenders upon re-entry to highlight strengths within the individual, and empower the individual to make choices and act in a prosocial manner. McWhirter (1994) defined empowerment as "the process by which people, organizations, or groups who are powerless (a) become aware of the power dynamics at work in their life context, (b) develop the skills and capacity for gaining some reasonable control over their lives, (c) exercise this control without infringing upon rights of others, and (d) support the empowerment of others in their community" (p. 12). Empowerment was a critical aspect of the proposed employment intervention. 


\section{Summary}

Based on the review of the literature, I established these goals for the intervention: (a) identifying skills and accomplishments related to work; (b) identification of job interests; (c) utilization of a computer-based career information system to learn more about different jobs; (d) development and practice of job-related skills such as interviewing and answering difficult questions about their criminal history; and (e) identification of barriers to employment, potential solutions to barriers, and the assessment and utilization of support persons and networks. The ultimate goal was to help ex-offenders identify and gain the skills necessary to secure and maintain employment. For the purposes of the dissertation study, data were collected to determine the effectiveness of the intervention to improve self-efficacy, problem-solving ability, and hope for the future. Long-term follow-up data on employment and recidivism will be extremely useful; however, due to time and cost commitments to gather follow-up data, the dissertation will focus on data from ex-offenders while still incarcerated. Following the conclusion of the dissertation study, I plan to continue following the sample to obtain employment and recidivism data.

\section{Research Questions and Hypotheses}

The research questions and hypotheses for the dissertation study were as follows: 
1. Will inmates at Oregon State Correctional Institute (OSCI) who participated in the employment intervention show greater improvements on career-search selfefficacy at posttest and one-month follow-up than inmates in a "treatment as usual" control group? I hypothesized that inmates at Oregon State Correctional Institute (OSCI) who participated in the employment intervention would show greater improvements on career-search self-efficacy at posttest and one-month follow-up than inmates in a "treatment as usual" control group. This hypothesis was tested using two 2 (treatment condition x control) x 2 (time) analysis of variance.

2. Will participants' in the employment intervention group perceive greater problem-solving ability at posttest and one-month follow-up than participants in the "treatment as usual" control group? I hypothesized participants' in the employment intervention group would perceive greater problem-solving ability at posttest and onemonth follow-up than participants in the "treatment as usual" control group. This hypothesis was tested using two 2 (treatment condition $\mathrm{x}$ control) $\mathrm{x} 2$ (time) analysis of variance.

3. Will participants' in the employment intervention be more hopeful immediately at posttest and one-month follow-up than participants in the "treatment as usual" control group? I hypothesized participants' in the employment intervention would be more hopeful immediately at posttest and one-month follow-up than participants in the "treatment as usual" control group._This hypothesis was tested using two 2 (treatment condition $\mathrm{x}$ control) $\mathrm{2}$ (time) analysis of variance. 


\section{CHAPTER II}

\section{METHODS}

\section{$\underline{\text { Research Design }}$}

This study utilized a randomized block design, with between-subjects and within-subjects measurements. Participants were matched based upon age and release date. There were two independent variables (IVs) and three dependent variables (DVs). The IVs were experimental group and time. Experimental group had two levels: (a) treatment and (b) "treatment as usual" control. The second IV time had three levels: (a) pretest, (b) posttest, and (c) one-month follow-up. The DVs were job search selfefficacy, perceived problem-solving ability, and hopefulness. Participants completed measures of these three variables at each of the three time periods.

\section{$\underline{\text { Participants }}$}

Participants in this research project were 77 adult male inmates (38 treatment, 39 control) housed at the Oregon Department of Corrections medium security release facility, the Oregon State Correctional Institute (OSCI) in Salem, Oregon. Participants were between the ages of 18 and 72 (mean $=32.55)$, able to write, speak, and read 
English, and were willing to participate for the duration of the study (approximately 3 months). Inmates were within 6 months of release.

\section{Procedures}

Inmates were recruited for voluntary participation in the study. Fliers were posted in the Portfolio Re-entry Program (PREP) program classroom. During PREP sessions, the Transitions Coordinator made announcements regarding the study. The announcements explained the study and asked for participants. Potential participants were informed that some would receive the intervention and some would not. Potential participants placed their names and inmate identification numbers on a sign-up sheet if they were interested in participating in the study. Potential participants then met with one of the trained group facilitators to determine if qualifications for the study were met. If qualifications were met, the participant read and signed an informed-consent document and completed the pretest measures. All study participants completed the pretest measures immediately following the screening interview with the research assistant. Participants in the treatment group completed the posttest measures at the conclusion of the final session. Participants in the control group session complete the posttest measures at the same time. All participants completed the follow-up assessments on or about October 10, 2007. All assessments were administered in a group format and were read aloud to the participants. 


\section{Random Assignment}

I assigned participants to an experimental group within 2 days after completing the pretest measures. First, I sorted the demographic data sheets by age. Starting with the youngest participants, I matched participants based upon age and release date. Release date was chosen because the PREP classes corresponded to the number of days left until release $(180,150,120,90,60,30)$; therefore, inmates with similar release dates attended a similar amount of PREP classes. Once participants were matched, they were randomly assigned to either the treatment or control group with the toss of a coin. I used a coin toss to randomly assign participants to groups to reduce the possibility of bias, or participant variation (Heppner, Kivlighan, \& Wampold, 1999).

\section{$\underline{\text { Intervention }}$}

Treatment as Usual

The "treatment as usual" group received the Portfolio Re-entry Program (PREP), a transitions program offered to all inmates prior to release at the facility. Approximately $25 \%$ of inmates in the Oregon Department of Corrections are transferred to the release center at OSCI when they are 6 months from release. All releasing inmates at OSCI are given the opportunity to participate in the Portfolio Re-Entry Program (PREP). Approximately $90 \%$ of releasing inmates choose to participate in the program. PREP provides inmates with a variety of skills and opportunities to learn about 
resources available to them once they are released. They are provided assistance in filling out Social Security applications, applications for the Oregon Health Plan, and in making plans for postrelease. The PREP intervention includes a resumé-writing component but does not address specific job-related issues such as interests, jobplanning processes, job search, interpersonal skills, etc. The PREP program consists of two monthly meetings at $180,150,120,90,60$, and 30 days prerelease. Both the treatment and "treatment as usual" control group participated in the PREP program.

\section{OPTIONS Intervention}

The findings in the literature indicate a need for empirically validated, theorybased career and employment interventions for ex-offenders. Using these findings as a basis, I modified a career counseling/employment preparation intervention for use with this population. The intervention, ACCESS (Chronister \& McWhirter, 2006), was originally designed for use with domestic violence survivors using Social Cognitive Career theory. Chronister and McWhirter (2006) tested the effectiveness of the ACCESS curriculum for 73 domestic violence survivors randomly assigned to a treatment or control condition. Participants were assessed on a variety of measures at pretest, posttest and 5-week follow-up. Participants showed an increase in career-search self-efficacy at posttest and follow-up as compared to the control group. The ACCESS curriculum contained the five key components of career counseling interventions identified by Brown and Krane (2000), as described below. I worked with Dr. 
Chronister to modify the ACCESS curriculum for use with male inmates. The modified curriculum was called OPTIONS. The modifications to the ACCESS curriculum included changing all the language to "ex-offender" rather than "survivor" and all pronouns to he/him instead of she/her. The introduction was changed to provide information about the struggles inmates face as they are released into the community. The tips and background information for the group facilitators were changed to be relevant for the offender population. It included information about working within the prison setting and facilitating the groups with offenders. Sessions 1, 2, 4 and 5 remained virtually unchanged, with the exception of the language and background information. All of the exercises and activities in these sessions remained the same. Session 3 underwent the most revision. The changes in Session 3 included the replacement of a relaxation exercise with an anger-management exercise, the change from a discussion about power and control to a discussion about risk factors for recidivism, and the replacement of an informational interview activity with a mock job interview activity. See Table 1 for a comparison of the ACCESS and OPTIONS curriculum.

The intervention took place Tuesday, July 10, through Thursday, September 13, 2007. The intervention consisted of five weekly group sessions lasting approximately 120 minutes each. Groups were initially comprised of six to seven inmates. The intervention focused on various aspects of the job-preparation process. Session 1 included an identification of and sharing of accomplishments and skills. Session 2 focused on identifying job interests and choices. Session 3 examined the reality of life 
TABLE 1. Distinguishing Characteristics of ACCESS and OPTIONS Curricula

\begin{tabular}{|c|c|c|}
\hline Session & ACCESS & OPTIONS \\
\hline \multirow[t]{6}{*}{1} & Description of group rules & Description of group rules \\
\hline & Introductions & Introductions \\
\hline & Identification of similarities & Identification of similarities \\
\hline & Discussion of accomplishments & Discussion of accomplishments \\
\hline & SKILLS assessment & SKILLS assessment \\
\hline & Skills discussion & Skills discussion \\
\hline \multirow[t]{4}{*}{2} & Discuss journal assignments & Discuss journal assignments \\
\hline & Identify career interests & Identify career interests \\
\hline & Interpret and discuss SKILLS results & Interpret and discuss SKILLS results \\
\hline & Use CIS to search for information & Use CIS to search for information \\
\hline \multirow[t]{5}{*}{3} & Discuss journal assignment & Discuss journal assignment \\
\hline & Discuss power and control & Discuss recidivism risk factors \\
\hline & Discuss feelings and physical experiences & Discuss feelings and physical experiences \\
\hline & Conduct relaxation exercise & Conduct anger management exercise \\
\hline & Lead information interview role-play & Lead job interview role play \\
\hline \multirow[t]{3}{*}{4} & Discuss information interview experience & Discuss mock job interview experience \\
\hline & $\begin{array}{l}\text { Discuss journal assignment and role of } \\
\text { support }\end{array}$ & $\begin{array}{l}\text { Discuss journal assignment and role of } \\
\text { support }\end{array}$ \\
\hline & Discuss activities for last group & Discuss activities for last group \\
\hline \multirow[t]{4}{*}{5} & Facilitate presentation of goals & Facilitate presentation of goals \\
\hline & Complete goals worksheets & Complete goals worksheets \\
\hline & $\begin{array}{l}\text { Discuss group members experience in } \\
\text { group }\end{array}$ & $\begin{array}{l}\text { Discuss group members experience in } \\
\text { group }\end{array}$ \\
\hline & Conclude & Conclude \\
\hline
\end{tabular}

as an ex-offender in terms of the job-search process. Inmates learned about how to disclose and discuss their criminal history and about dealing with the limitations of a felony record. Session 4 focused on utilizing support persons and building confidence in job-search abilities. The final session covered further ways to build and utilize a support 
network, and encouraged inmates to think about both their short-term and long-term goals.

\section{Fidelity of Treatment}

Fidelity of the treatment was ensured using a standardized treatment manual and utilizing a group leader checklist for each session to be sure each intended component was completed.

\section{Group Facilitation}

Intervention groups were co-facilitated by two Counseling Psychology doctoral students who had previous experience with group facilitation. Each of the six treatment groups were facilitated by the same facilitators. I recruited facilitators based on their experience facilitating groups, their desire and comfort level working with offenders, their experience working with marginalized individuals, and their availability during the scheduled intervention. I initially met with the group facilitators to discuss the logistics of the training and the intervention, and to schedule their training at the prison. I provided each with a facilitator manual and scheduled further training sessions, including one at the prison. The two facilitators traveled to the correctional institution in Salem and completed a 4-hour contractor training with the Assistant Warden. This training covered basic safety information as well as helpful tips for working within a correctional setting. I met with the group facilitators a total of three times for 2 to 2.5 
hours each to go over each intervention session, and provide training on working with inmates.

The two group facilitators were females between the ages of 25-30. One identified as European American; the other identified as biracial (European American and Cuban). Both had bachelor's degrees in Psychology or a closely related field, and relevant group-facilitation experience.

\section{$\underline{\text { Measures }}$}

\section{Demographic Form}

Background information was collected utilizing a demographic questionnaire. Items included age, race/ethnicity, education, length of sentence, previous number of incarcerations, prior theft convictions and program involvement while incarcerated.

\section{Career Search Self-Efficacy Scale}

The Career Search Self-Efficacy Scale (CSSE; Solberg et al., 1994) is a 35-item self-report measure used to assess an individual's confidence in performing careersearch tasks. Efficacy is assessed in four domains: Job Exploration, Interviewing, Networking, and Personal Exploration. A 10-point Likert scale is used by respondents to indicate their degree of confidence in their ability to complete certain tasks - e.g., utilizing their social network to gain employment (Solberg et al., 1994). Scores are calculated by summing all items. Scores range from $0-315$, with high scores indicating 
greater career-search self-efficacy. A sample of 229 community college students yielded a Cronbach's alpha reliability coefficient of .97 . Evidence of adequate convergent and discriminant validity was obtained in the same study (Solberg et al., 1994). The CSSE was used to measure ex-offenders' level of self-efficacy in regards to the career/job search process. In the present sample, Cronbach's alpha was used to generate a reliability coefficient of .98 . See Table 2 for reliability coefficients for the present study.

TABLE 2. Reliability Coefficients for the Present Sample

\begin{tabular}{cc}
\hline \hline Measures & Cronbach's alpha \\
\hline CSSE & .98 \\
PSI & .64 \\
HOPE & .49 \\
\hline
\end{tabular}

Note . Variable names: CSSE $=$ Career Search Self Efficacy; PSI $=$ Problem Solving Inventory; HOPE $=$ The Hope Scale.

The Problem Solving Inventory, Form B

The Problem Solving Inventory (PSI; Heppner, 1988) is a 35-item self-report measure used to assess an individual's perceived problem-solving ability. The PSI is comprised of three subscales: Problem Solving Confidence, Approach-Avoidance Style, and Personal Control. A 6-point Likert scale is used by respondents to indicate the degree to which they agree with statements such as the following: "When a solution to a problem has failed, I do not examine why it didn't work" (Heppner, 1988). The PSI scoring manual provides scoring templates. A total score is obtained by eliminating the 
three filer items, reverse-scoring 15 items, then summing all items. For the purpose of this study the subscale scores were not used. The overall total score was used to measure perceived problem-solving ability. Scores range from 32 to 192, with lower scores indicating higher levels of perceived problem-solving ability. The PSI has been empirically validated with a variety of different populations. Internal consistency computed using Cronbach's alpha ranged from .90-.91 with samples of undergraduate students, elderly adults, and French Canadian adults. Adequate concurrent and discriminant validity was obtained with the aforementioned populations. In the present sample, Cronbach's alpha was used to generate a reliability coefficient of .93.

\section{The Hope Scale}

The Hope Scale (Snyder et al., 1991) is a 12-item self-report measure used to assess an individual's level of hope. A 4-point Likert scale ranging from 1 (definitely false) to 4 (definitely true) was used by respondents to indicate the degree to which items such as "I can think of many ways to get out of a jam" and "I've been pretty successful in life" apply to them. The overall score was used to measure participants' level of hope. Scores range from 8-32, with higher scores indicating higher levels of hope. The Hope Scale was administered to six separate groups of University of Kansas psychology students, one outpatient clinical sample and one inpatient clinical sample. Internal consistency computed using Cronbach's alpha ranged from .75 to .84 with these populations. Adequate concurrent and discriminant validity was obtained by comparing 
the Hope Scale to a variety of different measures such as the Life Orientation Test and the Generalized Expectancy for Success Scale. In the present sample, Cronbach's alpha was used to generate a reliability coefficient of .84 . 


\section{CHAPTER III}

\section{RESULTS}

\section{Participants}

Participants included 77 men who were 18 years and older and who were incarcerated at the Oregon State Correctional Institute in Salem, Oregon. Participants completed the pretest measures, were matched based upon age and release date, and were then randomly assigned to either the OPTIONS treatment intervention $(n=38)$ or control group $(n=39)$. At the conclusion of the OPTIONS intervention, 61 participants completed posttest measures (treatment $n=31$; control $n=30$ ), and of those 61 participants, 47 participants returned 4 weeks later to complete follow-up measures (treatment intervention $n=23$; control $n=24$ ). Participant demographic information is summarized in Tables 3 and 4. A visual summary of significance of differences between the treatment and "treatment as usual" control group can be found in Table 5.

A total of six OPTIONS treatment interventions groups were conducted, and data were collected from July 10, 2007, to September 13,2007. Each of the six groups had a minimum of three participants who attended all five sessions. I did not close any groups due to lack of attendance. Of the 38 participants assigned to the OPTIONS treatment intervention group, 35 men attended the first group session, 30 attended the 
TABLE 3. Means and Standard Deviations for Continuous Demographic Variables

\begin{tabular}{lrrrrrrrrr}
\hline \hline & \multicolumn{2}{c}{ All participants } & & \multicolumn{2}{c}{ Control group } & & \multicolumn{2}{c}{ Treatment group } \\
\cline { 2 - 3 } Demographic variables & $M$ & $S D$ & & $M$ & $S D$ & & $M$ & $S D$ \\
\hline Age (years) & 32.55 & 10.48 & & 33.90 & 11.28 & & 31.14 & 9.51 \\
Length of Sentence (months) & 51.32 & 48.03 & & 47.64 & 42.89 & & 55.31 & 53.36 \\
Times incarcerated (adult) & 8.93 & 15.36 & & 6.78 & 11.33 & & 11.03 & 18.38 \\
Times incarcerated (juvenile) & 2.64 & 4.32 & & 2.82 & 4.53 & & 2.47 & 4.15 \\
Number of jobs held & 10.31 & 11.97 & & 11.94 & 15.23 & & 8.79 & 7.73 \\
\hline
\end{tabular}

TABLE 4. Frequencies and Percentages for Categorical Demographic Variables

\begin{tabular}{|c|c|c|c|c|c|c|}
\hline \multirow[b]{2}{*}{ Variables } & \multicolumn{2}{|c|}{ All participants } & \multicolumn{2}{|c|}{ Control group } & \multicolumn{2}{|c|}{ Treatment group } \\
\hline & $N$ & $\%$ & $N$ & $\%$ & $N$ & $\%$ \\
\hline \multicolumn{7}{|l|}{ Race/ethnicity } \\
\hline White/European American & 43 & 54.4 & 24 & 64.9 & 19 & 47.5 \\
\hline Asian/Pacific Islander & 2 & 2.5 & 0 & 0 & 2 & 5.4 \\
\hline Black/African American & 7 & 8.9 & 4 & 10.8 & 3 & 7.5 \\
\hline Latino & 9 & 11.4 & 4 & 10.8 & 5 & 12.5 \\
\hline Native/American Indian & 8 & 10.1 & 5 & 13.5 & 3 & 7.5 \\
\hline Biracial/multiracial & 8 & 10.1 & 0 & 0 & 8 & 20.0 \\
\hline \multicolumn{7}{|l|}{ Education } \\
\hline Eighth grade or less & 8 & 10.1 & 3 & 8.1 & 5 & 12.5 \\
\hline Some high school & 12 & 15.2 & 7 & 18.9 & 5 & 12.5 \\
\hline High school diploma/GED & 53 & 67.1 & 24 & 64.9 & 29 & 72.5 \\
\hline Associates degree & 3 & 3.8 & 3 & 8.1 & 0 & 0 \\
\hline Bachelors degree & 0 & 0 & 0 & 0 & 0 & 0 \\
\hline Graduate/Professional degree & 1 & 1.3 & 0 & 0 & 1 & 2.5 \\
\hline $\begin{array}{l}\text { Enrolled in school at time of } \\
\text { arrest }\end{array}$ & 8 & 10.0 & 2 & 5.4 & 6 & 15.0 \\
\hline \multicolumn{7}{|l|}{ Employment } \\
\hline Employed at time of arrest & 35 & 45.5 & 20 & 54.1 & 15 & 37.5 \\
\hline Full time & 28 & 35.4 & 13 & 35.1 & 15 & 37.5 \\
\hline Part-time (regular hours) & 2 & 2.5 & 1 & 2.7 & 1 & 2.5 \\
\hline Part-time (irregular hours) & 2 & 2.5 & 2 & 5.4 & 0 & 0 \\
\hline More than one job & 4 & 5.1 & 4 & 10.8 & 0 & 0 \\
\hline Paid taxes on last job & 49 & 62.0 & 21 & 56.8 & 28 & 70.0 \\
\hline
\end{tabular}


TABLE 5. Significance of Differences Between Treatment and Control Groups at Pretest, Posttest, and Follow-Up

\begin{tabular}{cccc}
\hline \hline Variable & Pretest & Posttest & Follow-up \\
\hline CSSE & Not significant $(p=.39)$ & Significant $(p<.001)$ & Significant $(p<.001)$ \\
PSI & Not significant $(p=.48)$ & Significant $(p=.03)$ & Significant $(p<.01)$ \\
HOPE & Not significant $(p=.30)$ & Significant $(p<.05)$ & Significant $(p<.01)$ \\
\hline
\end{tabular}

Note . Variable names: CSSE = Career Search Self Efficacy; PSI = Problem Solving Inventory; HOPE = The Hope Scale.

second session, 29 attended the third session, 30 attended the fourth session, and 31 attended the fifth session. Only one participant was dropped from the study after the first group due to risk of violent behavior in the group. His data were not reported and not used in any analyses.

\section{Preliminary Analyses and Results}

I conducted a series of independent samples $t$ tests to examine pretreatment equivalence of the experimental groups - i.e., treatment intervention $(n=38)$ and control $(n=39)$ groups. Results indicated that there were no pretreatment differences between the treatment group and the control group with respect to career-search selfefficacy $(\mathrm{CSSE}), t(75)=.86, p=.39$; problem solving $(\mathrm{PSI}), t(75)=-.71, p=.48$; and hopefulness $(\mathrm{HOPE}), t(75)=1.05, p=.30$. In addition, there were no significant differences between the groups for age, $t(75)=-1.15, p=.25$; sentence length $t(75)=$ $.69, p=.49$; number of times incarcerated as an adult, $t(75)=1.2, p=.23$; number of times incarcerated as a juvenile, $t(75)=-.34, p=.73$; educational attainment, $t(75)=$ - 
$.32, p=.75$; and number of jobs held, $t(75)=-1.05, p=.30$. Correlations, means, and standard deviations for pretest measures are presented in Table 6 .

TABLE 6. Means, Standard Deviations, and Correlations for All Measures at Pretest

\begin{tabular}{lcclll}
\hline \hline Variable & $M$ & $S D$ & 1 & 2 & 3 \\
\hline 1. CSSE & 209.67 & 63.92 & - & .01 & $.523^{* *}$ \\
2. PSI & 112.81 & 13.43 & .01 & - & .05 \\
3. HOPE & 31.35 & 4.00 & $.523^{* *}$ & .05 & - \\
\hline
\end{tabular}

Note. Variable names: CSSE $=$ Career Search Self Efficacy (score range $=0-315$ ); PSI $=$ Problem Solving Inventory (score range $=32-192$ ); HOPE $=$ The Hope Scale (score range $=8-32$ ).

\section{Attrition Analyses}

I used independent sample $t$ tests to determine differences between participants who completed the follow-up measures and those who did not. Results indicated that there were no statistically significant differences between participants who completed follow-up tests and those who did not complete follow-up tests with respect to pretest scores on problem solving (PSI), $t(75)=.28, p=.78$; career-search self-efficacy $(\mathrm{CSSE}), t(75)=-1.23, p=.60$; hopefulness (HOPE), $t(75)=-.71, p=.48$; and demographic information, including age, $t(74)=.47, p=.15$; number of times incarcerated as an adult, $t(73)=.93, p=.44$; number of times incarcerated as a juvenile, $t(74)=.02, p=.68$; education attainment, $t(75)=.12, p=.37$; and number of jobs held, $t(62)=.18, p=.90$. There was a significant group difference for sentence length, $t(73)=1.23, p=.04$. Participants who did not complete follow-up measures had shorter 
sentence lengths than those who completed follow-up measures, with a mean difference of 13.9 months.

I also conducted independent sample $t$ tests to determine differences between treatment participants who completed the OPTIONS treatment intervention and those who dropped out. Results indicated that there were no statistically significant differences between intervention completers and noncompleters with respect to pretest scores on career-search self-efficacy (CSSE), $t(36)=-.01, p=.77$; problem solving (PSI), $t(36)=-.26, p=.80$; hopefulness (HOPE), $t(36)=.72, p=.47$; and demographic variables, including age, $t(35)=.74, p=.06$; length of sentence, $t(34)=1.12, p=.07$; number of times incarcerated as an adult, $t(36)=.20, p=.46$; educational attainment, $t(36)=-.56, p=.13 ;$ and number of jobs held, $t(31)=.86, p=.25$.

Treatment Intervention Results

\section{Within-Group Differences}

I utilized analyses of variance to examine within-group changes on outcome variables from pretest to posttest, and from posttest to follow-up. ANOVA results for the OPTIONS treatment intervention group indicated there were statistically significant differences from pretest scores to posttest scores on career-search self-efficacy (CSSE), $F(1,67)=14.16, p<.001 ;$ perceived problem-solving ability (PSI), $F(1,68)=5.08$, $p=.03$; and hopefulness (HOPE), $F(1,67)=5.42, p=.02$. ANOVA results for the OPTIONS treatment intervention group indicated there were no statistically significant 
differences from posttest scores to follow-up scores on career-search self-efficacy $(\mathrm{CSSE}), F(1,52)=.290, p=.59$; perceived problem-solving ability (PSI), $F(1,53)=.03$, $p=.87$; and hopefulness (HOPE), $F(1,52)=.815, p=.371$. ANOVA results for the "treatment as usual" control group indicated there were no statistically significant differences from pretest scores to posttest scores on career-search self-efficacy (CSSE), $F(1,67)=.387, p=.54$; perceived problem-solving ability (PSI), $F(1,68)=.76, p=.39$; and hopefulness (HOPE), $F(1,67)=1.44, p=.234$. ANOVA results for the "treatment as usual" control group indicated there were no statistically significant differences from posttest scores to follow-up scores on career-search self-efficacy (CSSE), $F(1,52)=$ $.363, p=.55$; perceived problem-solving ability (PSI), $F(1,53)=.068, p=.80$; and hopefulness (HOPE), $F(1,52)=.094, p=.761$.

\section{Between-Group Differences}

I analyzed all data using 2 (experimental group) $\times 2$ (time) analyses of variance (ANOVAs). All ANOVA assumptions were met as verified by examination of boxplots and use of a randomized block design. I discuss treatment results in the order of my proposed research questions and hypotheses. Means and standard deviations on pretest, posttest, and follow-up measures are presented in Table 7. 
TABLE 7. Means and Standard Deviations for Dependent Measures Across Time

\begin{tabular}{lrrrrr}
\hline \hline & \multicolumn{2}{c}{ Control group } & & \multicolumn{2}{c}{ Treatment group } \\
\cline { 2 - 3 } \cline { 5 - 6 } Dependent measures & $M$ & $S D$ & & $M$ & $S D$ \\
\hline Pretest & & & & & \\
CSSE & 203.46 & 65.93 & & 216.04 & 62.01 \\
PSI & 98.20 & 22.38 & & 94.14 & 27.31 \\
HOPE & 21.97 & 4.57 & & 23.05 & 4.47 \\
Posttest & & & & & \\
CSSE & 213.24 & 63.24 & & 262.35 & 32.10 \\
PSI & 94.41 & 24.06 & & 79.52 & 26.72 \\
HOPE & 23.20 & 3.67 & & 25.25 & 3.08 \\
Follow-up & & & & \\
CSSE & 222.54 & 46.27 & & 267.10 & 31.90 \\
PSI & 91.92 & 22.59 & & 78.32 & 26.41 \\
HOPE & 23.50 & 3.46 & & 26.0 & 2.84 \\
\hline
\end{tabular}

Note. Variable names: CSSE $=$ Career Search Self Efficacy (score range $=0-315)$; PSI $=$ Problem Solving Inventory (score range $=32-192) ;$ HOPE $=$ The Hope Scale (score range $=8-32$ ).

Hypothesis 1

I hypothesized that inmates at the Oregon State Correctional Institute (OSCI) who participated in the OPTIONS employment treatment intervention would show greater improvements on career-search self-efficacy at posttest and 1-month follow-up than inmates in a "treatment as usual" control group. The first ANOVA showed a statistically significant main effect at posttest for career-search self-efficacy, $F(1,134)=$ $9.55, p<.001, \eta^{2}=.07$, Cohen's ES $=.89$, observed power $=.87$. The second ANOVA showed a statistically significant main effect at follow-up for career-search self-efficacy, $F(1,104)=27.71, p<.001, \eta^{2}=.21$, Cohen's ES $=.98$, observed power $=.99$. In sum, 
these ANOVA results supported Hypothesis 1 and indicated that participants in the OPTIONS treatment intervention had higher career-search self-efficacy scores at posttest and follow-up than participants who did not participate in the OPTIONS treatment intervention.

Hypothesis 2

I hypothesized that participants in the OPTIONS employment treatment intervention would perceive that they had greater problem-solving abilities at posttest and 1-month follow-up than participants in the "treatment as usual" control group. The first ANOVA showed a statistically significant main effect at posttest for problem solving $(\mathrm{PSI}), F(1,135)=4.86, p=.03, \eta^{2}=.04$, Cohen's $\mathrm{ES}=-.57$, observed power $=$ .59. The second ANOVA showed a statistically significant main effect at follow-up for problem solving $(\mathrm{PSI}), F(1,105)=8.62, p<.01, \eta^{2}=.08$, Cohen's ES $=-.54$, observed power $=.83$. In sum, these ANOVA results supported Hypothesis 2 and indicated that participants in the OPTIONS treatment intervention reported higher problem-solving abilities than men who did not participate in the OPTIONS treatment intervention.

Hypothesis 3

I hypothesized that participants in the OPTIONS treatment intervention would feel more hopeful at posttest and at 1-month follow-up than participants in the "treatment as usual" control group. The first ANOVA showed a statistically significant 
main effect at posttest for hopefulness (HOPE), $F(1,134)=5.07, p<.05, \eta^{2}=.03$, Cohen's ES $=.59$, observed power $=.61$. The second ANOVA showed a statistically significant main effect at follow-up for hopefulness (HOPE), $F(1,104)=12.67, p<.01$, $\eta^{2}=.11$, Cohen's ES $=.74$, observed power $=.94$. In sum, these ANOVA results supported Hypothesis 3 and indicated that participants in the OPTIONS treatment intervention reported feeling more hopeful at posttest and follow-up than participants who did not participate in the OPTIONS treatment intervention. 


\section{CHAPTER IV}

\section{DISCUSSION}

The purpose of this dissertation study was to adapt, deliver, and experimentally test the effectiveness of a research-based employment counseling group intervention that was designed to improve male inmates' ability to secure employment upon release. I hypothesized that OPTIONS participants would show greater improvements in careersearch self-efficacy, perceived problem-solving ability, and hopefulness as compared to the "treatment as usual" control group. In sum, study results indicated that participants who completed the OPTIONS intervention, in comparison with participants in the "treatment as usual" (TAU) control group, reported higher career-search self-efficacy, perceived problem-solving ability, and hopefulness at posttest and follow-up. Although over time the mean score trends for the control group participants seemed to increase for all three dependent variables, these apparent increases were not statistically significant. This chapter provides a discussion of the results and is organized by construct and hypothesis. A discussion of study strengths and weaknesses and directions for future research conclude this chapter. 


\section{Career-Search Self-Efficacy}

As hypothesized, career-search self-efficacy scores were higher at posttest and follow-up for participants who completed the OPTIONS intervention in comparison with participants in the "treatment as usual" (TAU) control group. That is, OPTIONS participants felt more confident than participants who did not complete the intervention in their ability to search for a job after completing OPTIONS. Scores continued to increase for both the treatment group and the TAU control group from posttest to follow-up. However, the difference in scores for the TAU control group was not statistically significant. Pretest CSSE scores for both groups were in the moderate range, indicating a moderate level of career-search self-efficacy. At posttest the control group scores had increased by several points, but remained in the moderate range, whereas the treatment group scores improved by over one standard deviation and were in the high range. Future research might examine how the OPTIONS intervention works with men who have extremely low or extremely high CSSE scores.

The theoretical foundation of the OPTIONS program is Social Cognitive Career Theory (SCCT), and intervention group activities were designed to enhance OPTIONS participants' perceptions of confidence regarding their job-search abilities. SCCT identifies specifically three key variables thought to enable individuals to exercise personal control of their vocational and educational pursuits, one of which was a primary focus of the OPTIONS intervention and this dissertation study: self-efficacy. According to SCCT, self-efficacy plays a crucial role in the identification of career 
interests and the formulation of goals related to education and employment (Lent, Brown, Hackett, 1994). Study results suggest that a brief and cost-effective employment intervention can, in fact, have a significant impact on enhancing male prison inmates' self-efficacy and potentially other relevant career-development factors, above and beyond standard community transition interventions offered in prisons. Focusing on self-efficacy development is critical because if an inmate has increased self-efficacy and feels more confident about his ability to find a job, social cognitive theory (Bandura, 1989) and SCCT purport that he will be more likely to search and apply for jobs, thereby increasing his chances of obtaining a job. In addition, increased self-efficacy may enhance an inmate's performance during interviews, further increasing his employment-related self-efficacy, performance accomplishments, and pursuit of his vocational goals.

In sum, present study results suggest that SCCT is, in fact, a viable theory that can be applied to the vocational development of male inmates and used as a theoretical foundation for brief, group interventions that are designed to address the employment search and vocational needs of male prison inmates who are transitioning to the community.

With regard to measurement of career-search self-efficacy, the Career Search Self Efficacy Scale (CSSE; Solberg et al., 1994) was used, which was the first time the CSSE has been used in an empirical study with ex-offenders. Psychometric results indicated that the CSSE is a valid tool to measure the career-search self-efficacy of ex- 
offenders, and results were similar to CSSE psychometric properties reported by with other samples (e.g., Solberg, Good, Fischer, Brown, \& Nord, 1995; Solberg, Grood, \& Nord, 1991; Solberg et al., 1994). As anticipated, the CSSE scores were positively correlated with HOPE scores, and negatively correlated with PSI scores. I had predicted as scores went up on the CSSE they would also increase on HOPE, as career-search self-efficacy and hopefulness are similar constructs. I anticipated scores on the CSSE and PSI would be negatively correlated, as lower scores on the PSI indicate higher levels of perceived problem-solving ability and would therefore likely decrease as the CSSE scores increased. The correlations of the CSSE to the HOPE and PSI indicate there is a connection between the three variables and that a relationship likely exists between levels of career-search self-efficacy, hopefulness, and perceived problem solving.

\section{Perceived Problem-Solving Ability}

As hypothesized, perceived problem-solving ability scores were lower at posttest and follow-up for participants who completed the OPTIONS intervention in comparison with participants in the treatment as usual (TAU) control group. That is, OPTIONS participants felt more confident in their ability to solve problems after completing the OPTIONS program than their peers who did not receive OPTIONS. Problem Solving Inventory (PSI) scores decreased for both the treatment group and the TAU control group from posttest to follow-up. However, the difference in scores for the TAU control 
group was not statistically significant. Pretest PSI scores for both groups were in the moderate range, indicating a moderate level perceived problem-solving ability. At posttest the control group scores had decreased by several points, but remained in the moderate range, whereas the treatment group scores decreased by over 14 points. Future research might examine how the OPTIONS intervention works with men who have extremely low or extremely high PSI scores.

Perceived problem-solving ability is self-efficacy related to a specific skill domain, and is a significant component of the foundation of problem-solving appraisal theory (Heppner, 2004). Heppner (2004) defined problem-solving appraisal as "one's general self-conception as an effective or ineffective problem-solver" (p. 347), and stated this self-conception affects anxiety levels, problem-solving styles, and the view of problems as challenges or threats.

OPTIONS participants' increased perceived problem-solving ability lends initial evidence that problem-solving appraisal theory is a useful theory for conceptualizing the problem-solving needs of inmates as they prepare to handle the challenges of re-entry, specifically the challenge of finding employment, and that problem-solving ability is directly associated with other relevant vocational development constructs that are important to individuals' career interests, skill, development, and achievements.

Research has shown that brief interventions that target problem solving result in increases in participants' perceived problem-solving ability (PSI scores; Heppner, 2004). Critical consciousness is the key component of the OPTIONS program. One of the 
critical consciousness group processes of the OPTIONS intervention was the problemposing component. The group leaders posed questions about possible problematic situations to the group and had them discuss possible prosocial responses to the difficulties. For example, the group discussed possible questions employers may ask about their criminal background and prosocial ways in which they can respond to such questions. The OPTIONS program also addressed problem solving through discussion of challenges related to finding employment, discussion of strategies to overcome specific challenges that inmates face, and through practice of problem-solving techniques such as using "I" statements, and present study results showed that the OPTIONS intervention resulted in significant increases in participants' perceived problem-solving ability. Results indicated perceived problem-solving ability was correlated with career-search self-efficacy and hopefulness, suggesting that as perceived problem-solving ability increases so does career-search self-efficacy and hopefulness. Targeting perceived problem-solving ability in future interventions is important. Upon re-entry to society, ex-offenders face many challenges-e.g., finding housing, reengaging with family and friends, and finding employment. Measuring levels of perceived problem-solving ability provides information about how an individual copes with problems and challenges. Changing men's perceived problem-solving ability will likely increase their self-efficacy related to problem solving and empower them to face the problems and challenges of re-entry, thereby increasing the likelihood they will be successfully reintegrate into society. Perceived problem-solving ability was measured 
using the Problem Solving Inventory (Heppner, 1988). The results of the present study provide further support for the psychometric properties of the PSI and the appropriate use of this measure with a prison inmate population. Perceived problem-solving ability is an important variable to measure for ex-offenders preparing for the challenges of community re-entry, specifically the challenges associated with obtaining employment. Measures of perceived problem-solving ability provide valuable information about the coping style of the person being assessed; that is, having information about how the individual perceives his ability to approach and cope with problems can inform interventions targeted at increasing his perceived efficacy.

OPTIONS participants and "treatment as usual" (TAU) control participants both had decreasing Problem Solving Inventory scores over time, although the changes for the TAU control group were not statistically significant. Participation in the "treatment as usual" Portfolio Re-entry Program (PREP) may have accounted for the change in scores over time for the TAU participants. However, both the OPTIONS participants and the TAU control group received the PREP intervention; therefore, if the change in scores over time was due to the PREP intervention, I would expect to see statistically significant changes from both groups. Intervention participants may have had an increase in perceived problem-solving ability due to the intervention itself because of the aforementioned group activities. The intervention targeted problem solving and aimed to increase participants' confidence in their ability to successfully navigate the challenges of obtaining employment. 


\section{Hopefulness}

As hypothesized, hopefulness scores were higher at posttest and follow-up for participants who completed the OPTIONS intervention in comparison to participants in the TAU control group. That is, OPTIONS participants felt more hopeful after completing the intervention than they did prior to entering the OPTIONS program, and in comparison with TAU participants. Hope scale (HOPE) scores increased for both the treatment group and the TAU control group from posttest to follow-up. However, the difference in scores for the TAU control group was not statistically significant.

Hopefulness is defined as a combination of perceived success in meeting past, present, and future goals, as well as perceived availability of successful pathways related to goals (Snyder et al., 1991), and hopefulness is closely aligned with the SCCT construct of outcome expectations. Outcome expectations are defined as "personal beliefs about probable response outcomes" (Lent, Brown, \& Hackett, 1994, p. 83). Although the OPTIONS intervention did not specifically address hopefulness, several components of the intervention were aimed to increase hopefulness indirectly. For example, a great deal of time was spent talking about goals and plans for the future. Many participants did not have long-term goals, or concrete plans for finding employment upon release from prison. The OPTIONS intervention provided support and guidance to allow the participants to identify long-term goals and assisted with the formulation of a plan to reach the goals, which could potentially increase hopefulness in 
several ways. First, the act of thinking about and setting goals is something some participants had never done before. The realization that they can indeed set goals and create a plan could potentially increase their hopefulness. Second, another aspect of the intervention was identifying strengths. The participants utilized the SKILLS assessment to identify and highlight the strengths they felt they possessed and those they felt they would most like to utilize in an employment setting. The criminal justice system and prison environment are not strengths based. Identifying and highlighting strengths was initially a struggle for many participants, some having been sent the message from both family members and society that they did not possess strengths. The act of increasing critical consciousness through identifying strengths as well as receiving support from other group members and the group facilitators during this process could potentially increase hopefulness and empower the participants to achieve their goals and become productive successful members of society upon release from prison.

Snyder et al. (1991) came to the empirical conclusion that individuals with higher levels of hopefulness were more likely to focus on success rather than failure, were more likely to set challenging goals for themselves, and were more likely to perceive a greater number of pathways to meet their goals. Snyder et al. also concluded individuals with higher levels of hopefulness had higher levels of self-efficacy and selfesteem as compared to individuals with lower levels of hopefulness. The results of the present study provide additional support for the theory promulgated by Snyder et al. and for targeting hopefulness in interventions with inmates. 
With regard to measurement, the results of the present study provide further support for the psychometric properties of the Hope Scale and its use with a male inmate population. As mentioned previously, higher levels of hopefulness are associated with higher levels of self-efficacy and self-esteem and with an increase in goal-directed activity. Measuring hopefulness as an inmate nears the end of his sentence may provide information about how the inmate feels about the upcoming transition and can identify inmates in need of further intervention to increase hopefulness.

Several possible explanations exist for the increase in hopefulness scores for OPTIONS participants. The OPTIONS intervention was different than the "treatment as usual" PREP intervention in several ways. OPTIONS groups were significantly smaller, with only six to seven participants per group versus PREP groups with up to 10 times as many participants. The small group size allowed for greater intimacy. In addition the critical consciousness components of the intervention included dialogue and group identification, which allow for greater intimacy and openness among group members. Intervention participants may have had an increase in hopefulness due to the intervention itself because of the aforementioned group activities.

\section{Additional Treatment Considerations}

Although many plausible alternative explanations for significant results can be ruled out due to the tight control provided by the research design and statistical analyses, there are several possible explanations for significant results. First, the two OPTIONS 
group facilitators were not prison staff members and were not affiliated with the prison in any capacity other than to facilitate the group intervention. It is possible that the group facilitators' lack of association with the prison allowed group members to trust them more, and to open up and disclose more than they would have with prison staff facilitating the group. Second, an essential and inseparable component of the OPTIONS program is focused on building a cohesive group in which members identify with one another and develop close rapport with each other and facilitators through dialogue. Such a relationship intervention focus may have been more critical than the OPTIONS intervention curriculum content, but the present study "package" research design does not allow me to isolate which component(s) were most effective.

Third, the small size of the OPTIONS groups may have impacted the results. The groups were very small in comparison to PREP program groups, which included classes of $75+$ participants. The OPTIONS program was comprised of fewer than seven group members, allowing for more interpersonal interactions among the group members and between the group members and facilitators. Fourth, the physical set-up of the OPTIONS group also may have impacted study findings. The PREP program takes place in a large classroom. PREP participants sit in individual desks around the room. PREP participants tend to sit with other inmates with whom they are familiar and tend not to associate with participants with whom they are not familiar. The OPTIONS program setting was set up in a small tight circle, with the group facilitators as part of the circle. This physical set-up of the OPTIONS intervention room seemed to create a 
more intimate environment, again allowing for more intimate discussion and dialogue during intervention groups. These previously described differences in group size and physical space may have influenced the effectiveness of the OPTIONS intervention in comparison with the PREP program. Finally, participants in the OPTIONS intervention also may have perceived higher levels of problem solving over time as they successfully solved problems and increased hopefulness as their release date approached. Although this explanation is plausible, however, both the treatment and TAU control groups had equal perceived problem-solving ability and hopefulness scores at pretest, and only intervention participants' scores changed significantly from pre- to posttest. This difference was maintained at follow-up. If the significant increase in perceived problemsolving ability and hopefulness was due to the impending release date, I would expect to see the same magnitude of increase in the control group at posttest and follow-up. Therefore, it seems likely that perceived problem-solving ability and hopefulness increased significantly as a result of the intervention rather than time to release.

\section{Contextual Factors Impacting Study Procedures}

One of the first major pitfalls in the study was the sudden departure of the Oregon State Correctional Institute's Transition Coordinator. Her departure created problems on several levels: First, the woman hired to take her place had no prior knowledge of the study. Prior to the start of the intervention, the PREP program was discontinued for several months so that revisions to the program could be made. The 
PREP program resumed in June of 2007 and was significantly different from the previous program. Also, the departure of the former coordinator created a situation in which other staff felt vulnerable. Many staff members were leery of having a student come in to conduct research during this vulnerable time. Fortunately, the prison administrators were highly supportive and wanted to be sure my project could continue despite the turmoil associated with the coordinator change.

The recruitment of participants did not happen as originally planned. Despite my communications with the new coordinator about the importance of all inmates being incarcerated throughout the duration of the study, 14 participants had release dates prior to the end of the study, resulting in the loss of their follow-up data, and in some cases even the posttest data.

Security clearance for the group facilitators was an issue as well. At the start of the study, prison administration stated they did not want to issue Department of Corrections IDs to the group facilitators due to the short time frame of the study. This meant that they were considered visitors, and therefore had to have a staff escort at all times while in the prison. This created many difficulties in that a staff person had to escort them in and out of the facility and be present with them at all times inside the institution. This created a great deal of stress for the Transition Coordinator. Ultimately the facilitators were given DOC IDs, resulting in less stress and greater cooperation from the Transition Coordinator. 
Several logistical difficulties arose during the study. For the participants to come to the group, they had to be put on a "call-out" list the night before each group. Call-outs happen on the half hour, so sometimes inmates would arrive 30 minutes early to group sessions and sometimes they would be a few minutes late. Several times the groups started late as a result. Several times the inmates were not placed on the call-out list the night before. The group facilitators would arrive and be waiting for the group members, only to have them not show up. The coordinator then had to call each individual participants unit and request they be sent to the classroom. This resulted in significant delays in start times. However, groups did not start until all members were present; therefore, all members received the same dosage of the intervention.

Week 2 of the intervention calls for the use of computers. Unfortunately computers were not available the second week of the intervention. This resulted in the group facilitators having to negotiate with the academic department staff to arrange time for the inmates to access the computers. Originally the plan was to switch Weeks 2 and 3 in the curriculum and use the computers during the group intervention the following week. However, the computers were again unavailable. The group facilitators arranged "open lab" time for the individuals in the groups to come on their own. Not all group members were able to attend open lab time; therefore, not all members received the CIS component of the intervention. No attendance record was kept of who received or did not receive the CIS component; therefore, I was unable to conduct statistical analyses to 
determine if differences existed between participants utilizing the CIS component and those who did not.

\section{$\underline{\text { Study Implications }}$}

The OPTIONS intervention was adapted based on the original ACCESS intervention (Chronister, 2005), which was created using Social Cognitive Career Theory and the meta-analysis results of Brown and Krane (2000). Results showed that (a) vocational interventions lasting four to five sessions resulted in the most positive career outcomes for intervention participants; and (b) the most effective career interventions were comprised of the following five intervention components: written exercises, information about the world of work, individualized interpretation of assessments and feedback, strategies for finding employment support, and role modeling.

These five intervention components, which were included in the OPTIONS intervention program, have been highlighted as key components that dramatically improved the effectiveness of career-choice interventions and are consistent with best practices in ex-offender programming (Andrews et al., 1990; Brown \& Krane, 2000;

Chronister \& McWhirter, 2006; Gendreau, 1995, 1996). The results of the present study support the meta-analysis findings of Brown and Krane showing that four to five sessions, as well as a group intervention comprised of all five critical intervention components, were enough to result in statistically significant improvements in career- 
search self-efficacy, perceived problem-solving ability, and hopefulness for exoffenders.

Learning how to navigate multiple environments while dealing with the stressors associated with re-entry can be overwhelming to ex-offenders. Several components of the OPTIONS employment preparation intervention addressed these needs and empowered the individual to exert personal agency in decision-making and action. The two components are critical consciousness and empowerment theory.

Six components were utilized in the intervention to enhance critical consciousness. Components included (a) dialogue (exchange of and reflection upon ideas); (b) group identification (increase social support); (c) problem posing (reflecting upon beliefs and realities held by individuals); (d) identifying contradictions (naming discrepancies); (e) power analysis (examining how power is used and distributed; McWhirter, 1994); and (f) critical self-reflection (increasing awareness of power, privilege, and ability to act; Chronister \& McWhirter, 2006). The critical consciousness aspect of the intervention aimed to increase awareness and understanding of the skills of the inmate, the impact of crime and imprisonment on their career development, and an increased awareness and understanding of the power dynamics at work in their lives (Chronister \& McWhirter, 2006).

The results of this dissertation study provide further support to the literature on best practices in offender programming. The OPTIONS program, in part, utilized cognitive and behavioral techniques. The program targeted participants' thoughts about 
types of employment, their individual strengths, limitations of a felony record, and ability to set and achieve goals. Targeting such cognitive processes is consistent with the empirical literature supporting $\mathrm{CBT}$ and cognitive interventions as the most effective types of interventions with offenders (Andrews et al., 1990; Gendreau, 1995, 1996). Scholars have identified key components of effective re-entry programs. Key components include cognitive behavioral interventions, modeling of prosocial skills and behaviors, and adhering to the responsivity principle in that the intervention teaches new prosocial skills to the offender (Bourgon \& Armstrong, 2005; Gendreau, 1995, 1996). Programs also need to target the criminogenic needs of ex-offenders, which can be defined as those needs that, when changed, alter the probability of recidivism (Andrews et al., 1990; Bourgon \& Armstrong, 2005; Gendreau, 1995, 1996). Unemployment is a major criminogenic need. Being that the OPTIONS intervention targeted employment, it is consistent with this best practice. The OPTIONS taught several prosocial skills, including anger-management techniques and strategies for a successful employment interview.

The results of this dissertation study address a gap in the current literature identified by Vernick and Reardon (2001). Vernick and Reardon highlighted the lack of attention to career development in current job and vocational training programs for exoffenders. This study provides information about career development as it relates to exoffenders and provides meaningful data to support targeting career development in future studies. The importance of career development for ex-offenders is a critical area 
worthy of further exploration. Incarceration has a significant impact on the career development of ex-offenders, in many cases severely retarding the process.

\section{Inmate Feedback}

I created a feedback form for participants to complete during the last session of the intervention. Many participants expressed feeling more hopeful about their re-entry into society, knowing that there were people in the community who cared about their success and who wanted them to do well. The inmate participants were very excited to share their intervention experiences and asked how they could be of help to be sure that more inmates would benefit from the material presented.

Several participants commented that they truly enjoyed this intervention experience because they were placed in groups with inmates they "wouldn't normally run with." These participants expressed that the diversity of the groups was one of the most beneficial aspects of the intervention. They stated they enjoyed and benefited from hearing about each other's paths, goals, dreams, and careers. In the prison culture there are often pressures for an inmate to associate only with members of his own race. The participants were randomly assigned to one of the six treatment groups. Each group was diverse in terms of age, race, length of sentence, etc. The inmates' responses indicate that the group members became quite cohesive in several of the OPTIONS groups. Prior to the start of the intervention, I experienced some nervousness regarding the groups' racially diverse nature. The phenomenon that occurred went above and beyond my best 
case prediction. The groups appeared to form bonds with one another, as evidenced by their behavior in the groups, their verbal feedback and their reported behavior within the institution, namely acknowledging one another outside of the group setting. Both the heterogeneity of the treatment groups as well as group cohesion appears to have contributed to the efficacy of the OPTIONS intervention, warranting further empirical examination of these phenomena.

The small size of the treatment groups was highlighted as a benefit by the participants, and may have contributed to the efficacy of the OPTIONS intervention. Each OPTIONS group consisted of six-seven participants. The "treatment as usual" PREP program consists of 75-90 group members at any given time, creating a less intimate environment. The smaller group size allows for more intimate conversations and gives participants adequate time to share and learn from other group members.

The group members highlighted aspects of the intervention they felt worked well—namely, highlighting and discussing their skills and accomplishments, using the individualized information from the SKILLS assessment to search CIS and learn about possible jobs, the discussion of existing supports and how to build support systems, the mock interviews, discussion of the journal exercises, and the discussion of goals. Participants stated that they benefited from in-depth examination of their own career paths and goals.

Group members expressed a desire for the intervention to be longer, to have more training in resumé writing, and more practice role-playing job interviews. The 
inmates expressed the desire to have more conversations about handling the pressures of release such as finding a job quickly, re-engaging with their family and friends, avoiding peers and situations that are negative, reporting to their parole or probation officer, staying sober, and being accepted by society. They also expressed the desire for more indepth training on recognizing factors and situations that upset them and learning tools to cope. The group members also expressed the desire for more information on where to go to obtain the skills necessary for the jobs they wanted.

Group members varied significantly in terms of the employment goals and plans for the future. Some inmates had very clear employment goals and had been planning for ways to reach their goals upon release. Other inmates had not even considered what type of job they would try to pursue or how they would pursue it. Several inmates commented they thought they had thought through a plan, but the OPTIONS program made them realize they had much more planning that they needed to do.

The group members reported that they enjoyed and benefited from learning to use "I" statements. The week following the "I" statement activity, one group member commented to the group leaders that he had used "I" statements with his "cellie" (roommate) and with his significant other, and that they had been very effective.

\section{Feedback From Group Facilitators}

Each week I met for several hours with the two group facilitators to debrief. Throughout the process they provided feedback about the activities that worked well, 
and those that were more difficult. Both group facilitators greatly enjoyed the experience of facilitating the groups and felt they had gained clinical skills, knowledge of working in the prison environment, and awareness of social justice issues pertaining to inmates' transitioning into the community. The group facilitators felt they were able to form strong working alliances with the group members and were able to build rapport and trust quickly, which is not easy to do in a prison environment. The facilitators commented that group members seemed to support and encourage each other both during the group and between-group sessions. The group members helped each other stay focused and on track during the group activities, and would openly redirect group members who were getting off topic. The facilitators expressed great frustration at the many barriers to change within the prison environment and were able to better understand the challenges faced by inmates as they prepare to transition into the community.

\section{Strengths and Limitations}

There were several strengths of this dissertation study. First, a strength of this study was the use of a randomized block design, with participants matched on age and release date. This research design minimized error variance and pretreatment differences, and allows for strong generalizability of the results. Second, I implemented the OPTIONS intervention and examined its effectiveness in a naturalistic setting. The intervention took place in the prison environment, incorporating and overcoming many 
challenges inherent in conducting programs and/or research within a correctional setting. This allows for the study to be applicable in other correctional settings and is evidence of collaborative, translational research. Third, this dissertation study was the first time a manualized employment-preparation treatment intervention was adapted specifically for inmates preparing for release back into the community, making this a useful starting point for future research with other incarcerated folks like women, youth, etc. Fourth, this was the first time SCCT has been examined with a male inmate sample. Due to the lack of research regarding career-development theory with adult male offenders, this study further supports the utility of SCCT with diverse populations and provides a foundation for creation of theory-based programming for ex-offenders preparing to enter the workforce. Finally, this was the first time the measures in this study (CSSE, PSI, and HOPE) were used with male inmates.

There also were limitations of this dissertation study that deserve consideration. First, I did not collect data on employment and recidivism postrelease. Although the results were significant for all three independent variables, the true impact of the intervention cannot be fully known until longitudinal data have been collected on employment and recidivism for the treatment and control groups.

Second, a limitation was participant attrition. Initially, 79 potential participants came to the information session. Only two inmates declined to participate after learning more about the study, leaving a total of 77 inmates to complete the pretest measures and be randomly assigned to the treatment and control groups. I do not have information 
regarding how many inmates met the criteria for the study but chose not to sign up for the information session. At the conclusion of the OPTIONS treatment program, 79\% of the original sample $(n=61)$ returned to complete the posttest measures. Four weeks after the conclusion of the treatment, $77 \%$ of the participants who completed posttest measures returned to complete the follow-up measures $(n=47)$. Overall $61 \%$ of the original sample completed the study for an attrition rate of $39 \%$.

The attrition rate was higher than expected and could potentially have impacted the power to detect significant changes in some outcomes. However, the attrition rate was the same for the treatment and TAU control group, and there were no differences on outcome or pretest variables between participants who remained in the study and those who dropped out. This limitation did not affect the significance of the results, as adequate observed power was obtained for each variable.

As is often the case when one conducts community-based research, several difficulties arose during the course of the study that could potentially impact the validity of the study. These difficulties, as well as how they were addressed, are discussed in detail in an earlier section and will be summarized here. There was a staffing change resulting in a new Transition Coordinator who was unfamiliar with the project. Several participants $(n=14)$ with release dates prior to the completion of the study were recruited, resulting in the loss of their follow-up data. Inmate call-outs were often untimely and incorrect. Group facilitators were not initially issued DOC IDs and had to be escorted by a staff person at all times. And finally, computers were not available 
during the group intervention, resulting in some inmates not being able to utilize the CIS program.

\section{$\underline{\text { Recommendations for Future Research }}$}

\section{Measurement}

The creation and validation of measures that more accurately target attitudes and behaviors of inmates in reference to employment would help to increase the statistical power. To date, there are no career- or employment-related measures designed for and normed with inmates preparing for release. In addition, it may be useful to measure constructs such as criminal thinking, outcome expectations, and group cohesion. The concept of criminal thinking is widely discussed in the criminal justice literature and has been the focus of some cognitive behavioral interventions. Criminal thinking has been linked to the act of committing crime. In the future it may be helpful to measure criminal thinking before and after participation in the OPTIONS intervention. Outcome expectations are one of the three key variables in Social Cognitive Career Theory (SCCT). Feedback from both the group facilitators and the OPTIONS program participants indicate that group cohesion was an important factor in the efficacy of the OPTIONS intervention. Measurement of group cohesion would provide valuable information as to whether or not the OPTIONS intervention does indeed impact group cohesion. Development and empirical validation of an outcome expectations measure 
for ex-offenders preparing for release could provide further evidence of the utility of SCCT with ex-offenders and inform future interventions.

\section{Theory}

A great deal of literature exists examining the efficacy of vocational and job skill training programs; however, these studies lack attention to career development (e.g., identification of skills and interests, and obtainment of information regarding the world of work) and preparation for obtaining a job. Many career-development theories exist; however, Social Cognitive Career Theory seems to be a viable theory in terms of conceptualizing the career development of ex-offenders, and the potential impact of incarceration on career development. Further research is needed to better understand Social Cognitive Career Theory as it relates specifically to ex-offenders. To date, the literature is void of career-development theory-based interventions for ex-offenders. The present dissertation study aims to fill this void. However, future research should examine efficacy of the present SCCT-based intervention on other key SCCT variables such as outcome expectations and goals.

\section{Intervention}

First, I recommend following the cohort of participants from this study and gathering data on employment and its potential effects on recidivism. Second, I recommend the replication of this study with a larger sample from different correctional 
facilities - including local jails, other facilities in the State of Oregon, facilities in other states, and the Federal Bureau of Prisons - to compare the effects of the intervention on inmates in different correctional settings. Third, I recommend researching the efficacy of theory-based employment-preparation interventions that begin while an inmate is incarcerated and continue with a community reintegration component once an inmate leaves the prison setting. Fourth, I recommend experimenting with the timing of the intervention such as delivering the intervention 2 hours a day for one week, and delivering the intervention at differing time points as inmates prepare to release-e.g., one year prior to release versus one month prior to release. Finally, I recommend experimenting with different aspects of the intervention such as delivering the intervention to a larger group of participants at one time, experimenting with different physical configurations of the room-e.g., being in a tightly formed circle, being spread out with desks and tables between participants and facilitators, etc. I recommend experimenting with various additive and dismantling designs to help determine which components are most effective.

\section{Employment}

I recommend collecting data on employment for ex-offenders after release from prison. As mentioned previously, little information exists about rates of employment for offenders once they are released from prison. Discussion of the relationship between employment and recidivism is difficult if little is known about the rates of employment 
for ex-offenders. Gathering more data on the rates of employment and type of employment (manual labor, retail sales, call center, fast food service, etc.) and wages is crucial to gain a better understanding of the relationship between successful employment and recidivism as well as the critical components of interventions that assist inmates in finding and sustaining employment.

\section{$\underline{\text { Implications for Practice }}$}

Different audiences can benefit in different ways from the information provided by the present dissertation study. Below I have highlighted ways in which psychologists, prison administrators, policymakers, and community agencies can benefit from the findings of the present dissertation study.

The results of the present study provide a strong argument for psychology's involvement in the re-entry process for ex-offenders. Often this process is left up to the education department and parole and probation counselors. The results of this study support psychology's involvement in targeting distorted thinking and providing support and encouragement as well as teaching prosocial skills that will assist the ex-offender in meeting their goals, thus potentially decreasing the likelihood of recidivism. The findings of this study can inform the work psychologists do with ex-offenders preparing for employment and community re-entry. It helps to identify areas to focus on in the reentry preparation process, and provides a model of empowerment for the ex-offender. 
Prison administrators are interested in learning more about effective programming that will help support ex-offenders as they transition to the community. The OPTIONS program is cost effective, is not time consuming, and can easily be conducted within the prison setting. Policymakers are looking for ways to decrease rates of recidivism. As the prisons fill at an alarming rate, and funding is scarce for building new facilities to house the overwhelming numbers of inmates, attention must shift to resources that will provide the ex-offenders with skills that will assist them with being successful upon re-entry. The results of this study provide data for policymakers on an effective program that has the potential to increase rates of employment among exoffenders. Longitudinal data are needed to support the link to higher rates of employment and lower rates of recidivism. The results of this dissertation study can inform community agencies that provide assistance to ex-offenders upon re-entry. Lane Community College (LCC) is a perfect example. The college has seen an explosion in enrollment of ex-offenders in recent years. The academic advisors and career counselors are hungry for information that will inform their work with students desiring to further their education but who lack the knowledge about what limitations they may face due to their felony record. Since the conclusion of the present dissertation study, I have been invited to speak two times at LCC about effective ways to provide support to exoffenders as they prepare for employment. The two presentations at LCC have led to the formation of collaborative relationships between various LCC departments and community agencies within Lane County to provide support to ex-offenders 
transitioning into the workforce. In addition, the presentations at LCC have led to the formation of a resource binder in the LCC career and employment services department specifically created for ex-offenders.

The majority of ex-offenders want to work. Many desire to be contributing members of society and to have a fresh, clean start at life. However, the multiple challenges of re-entry present a roadblock to some that seems insurmountable. The OPTIONS intervention can assist ex-offenders desiring a job and can potentially alter the way they view their strengths, their resources and their supports and empower them to take risks and learn new skills. The OPTIONS intervention can normalize the stresses related to finding employment and encourages participants to seek help in their job search.

The potential implications of this type of intervention allow inmates to provide support for each other and may create inherent support systems for ex-offenders. Moreover, they may create/motivate ex-offenders to take action to further this cause and support each other on the outside. In addition, this type of intervention may create a movement toward activism and ownership instead of passivity and blame.

The results of the present dissertation study support the following conclusions about interventions with ex-offenders. Interventions with ex-offenders should be informed by Social Cognitive Career Theory and target the three variables measured in this study: career-search self-efficacy, perceived problem-solving ability, and hopefulness. Interventions targeting self-efficacy should be studied further to investigate 
the link between increased career-search self-efficacy and career-related behaviors such as increased career-search activity. If inmates have increased self-efficacy and feel more confident about their ability to find a job, they may be more likely to apply for jobs and take greater risks in terms of the types of jobs they apply for. This will likely increase their chances of obtaining a job. In addition, their increased self-confidence may be apparent in their interviews and may make employers more interested in hiring them; however, further research is needed to support these claims.

Problem-solving ability is an important component of an effective employmentpreparation intervention, as ex-offenders are likely to encounter many challenges and setbacks in the job-search process. Ex-offenders will likely encounter normal everyday challenges once they have obtained employment. Successful problem-solving ability may increase the likelihood of handling employment-related problems in a prosocial manner.

Hopefulness is an important variable. It is an indicator of the degree to which individuals believe they can achieve their goals and generate possible pathways to goal attainment. Findings of the present study support targeting hopefulness in future assessment and intervention. Targeting hopefulness in interventions will likely lead to an increase in goal-directed activity, further assisting the ex-offender as they take on the challenge of obtaining employment upon release. 


\section{$\underline{\text { Summary and Conclusions }}$}

The impact of incarceration on an individual's career development is significant. For example, in the present study there was great diversity in terms of number of times participants had been incarcerated and the number of jobs held. Some members of the study had been in and out of institutions since they were juveniles and had never had a job. Others had been in and out of prison and had worked sporadically in between incarcerations, whereas others had been incarcerated for $20+$ years and therefore had a huge gap in their employment history. Many ex-offenders lack information about how to find a job, or who will hire them. With limited critical thinking or problem-solving skills, they assume defeat before beginning. Targeting thought distortions and decreasing anxiety, ambivalence and ambiguity about the process of employment may increase hopefulness, leading to greater career-search self-efficacy and thereby potentially leading to higher levels of employment.

With the prison population growing at an alarming rate, attention must be paid to programs that are effective at increasing rates of employment for inmates, which in turn may reduce recidivism, keeping our communities and society safer. The results of this study showed the OPTIONS program, a Social Cognitive Career Theory-based intervention, is effective at increasing participants' career-search self-efficacy, perceived problem-solving ability, and hopefulness. In addition to providing a much needed resource to inmates preparing to transition to the community, this study makes a contribution to a relatively small amount of research on effective job-preparation tools 
for inmates. No other studies were found that examined an employment-preparation intervention of this nature for male inmates. Future research and practice may be enhanced by following the cohort of participants from this study and gathering data on employment and its potential effects on recidivism, as well as replication of this study with a larger sample from different correctional facilities_-including local jails, other facilities in the State of Oregon, facilities in other states, and the Federal Bureau of Prisons - to compare the effects of the intervention on inmates in different correctional settings. 
APPENDIX A

DEMOGRAPHIC QUESTIONNAIRE 


\section{Demographic Questionnaire}

Age?

How would you describe your race or ethnicity? (Please circle all that apply)
a. Asian/Pacific Islander
b. Alaskan Native
c. Black/African American
d. Latino/a
e. Native American/American Indian
f. White/European
g. Other

How many months is your sentence?

What is your projected release date?

How many times have you been incarcerated in prison or jail as an adult (since the age of 18$)$ ?

How many times were you incarcerated before the age of $18 ?$

Have any of your parents or other caregivers been incarcerated? YES NO

Do you have any prior theft convictions? YES NO

How much education do you have?
a. Eighth grade or less
b. Some high school
c. High school diploma or GED
d. Associate's degree
e. Bachelor's degree
f. Graduate or professional degree

Were you enrolled in school at the time of your current arrest? YES NO Were you employed at the time of your arrest? YES NO 
If yes, please mark all that apply:

Full time (more than 30 hours a week at one job)

Part time (regular hours)

Part time (irregular, day work)

More than one job

Did you pay taxes on the income you earned from your last job? YES NO What was your last job?

How many different jobs have you held?

Which of the following groups have you attending while incarcerated?

a. I have not attended any groups or programs

b. I have attended the following groups and/or programs (please mark with an X)

1. Alcoholics Anonymous

2. Narcotics Anonymous

3. Drug Treatment 
APPENDIX B

MEASURES 


\section{Career-Search Self-efficacy}

Directions: Please circle an answer to indicate how confident you are in performing each of the tasks listed below.

\section{HOW CONFIDENT ARE YOU IN YOUR ABILITY TO:}

\section{VERY LITTLE}

1. Identify and evaluate your career values.

2. Meet new people in career of interest.

3. Develop an effective cover letter to be mailed to employers.

4. Evaluate a job during an interview.

5. Conduct an information interview.

6. Identify and evaluate your career preferences

7. Clarify and examine your personal values.

8. Utilize your social networks to gain employment.

9. Identify and evaluate your personal values.

10. Market your skills and abilities to an employer.

11. Use your social network to identify job opportunities.

12. Integrate your knowledge of yourself, the beliefs and values of others, and your career information into realistic and satisfying career planning.

13. Develop realistic strategies for locating and securing employment.

14. Join organizations that have a career emphasis.

$\begin{array}{llllllllll}0 & 1 & 2 & 3 & 4 & 5 & 6 & 7 & 8 & 9\end{array}$

$\begin{array}{llllllllll}0 & 1 & 2 & 3 & 4 & 5 & 6 & 7 & 8 & 9\end{array}$

$\begin{array}{llllllllll}0 & 1 & 2 & 3 & 4 & 5 & 6 & 7 & 8 & 9\end{array}$

$\begin{array}{llllllllll}0 & 1 & 2 & 3 & 4 & 5 & 6 & 7 & 8 & 9\end{array}$

$\begin{array}{llllllllll}0 & 1 & 2 & 3 & 4 & 5 & 6 & 7 & 8 & 9\end{array}$

$\begin{array}{llllllllll}0 & 1 & 2 & 3 & 4 & 5 & 6 & 7 & 8 & 9\end{array}$

$\begin{array}{llllllllll}0 & 1 & 2 & 3 & 4 & 5 & 6 & 7 & 8 & 9\end{array}$

$\begin{array}{llllllllll}0 & 1 & 2 & 3 & 4 & 5 & 6 & 7 & 8 & 9\end{array}$

$\begin{array}{llllllllll}0 & 1 & 2 & 3 & 4 & 5 & 6 & 7 & 8 & 9\end{array}$

$\begin{array}{llllllllll}0 & 1 & 2 & 3 & 4 & 5 & 6 & 7 & 8 & 9\end{array}$

$\begin{array}{llllllllll}0 & 1 & 2 & 3 & 4 & 5 & 6 & 7 & 8 & 9\end{array}$

$\begin{array}{llllllllll}0 & 1 & 2 & 3 & 4 & 5 & 6 & 7 & 8 & 9\end{array}$

$\begin{array}{llllllllll}0 & 1 & 2 & 3 & 4 & 5 & 6 & 7 & 8 & 9\end{array}$

$\begin{array}{llllllllll}0 & 1 & 2 & 3 & 4 & 5 & 6 & 7 & 8 & 9\end{array}$ 
HOW CONFIDENT ARE YOU IN YOUR ABILITY TO:

VERY LITTLE

$\underline{\text { VERY MUCH }}$

15. Develop skills you can use across a lifetime of career planning.

$$
\begin{array}{llllllllll}
0 & 1 & 2 & 3 & 4 & 5 & 6 & 7 & 8 & 9
\end{array}
$$

16. Dress in a way that communicates success during a job interview.

$\begin{array}{llllllllll}0 & 1 & 2 & 3 & 4 & 5 & 6 & 7 & 8 & 9\end{array}$

17. Identify the resources you need to find in the career you want.

$\begin{array}{llllllllll}0 & 1 & 2 & 3 & 4 & 5 & 6 & 7 & 8 & 9\end{array}$

18. Contact a personnel office to secure a job interview.

$\begin{array}{llllllllll}0 & 1 & 2 & 3 & 4 & 5 & 6 & 7 & 8 & 9\end{array}$

19. Know where to find information about potential employers in order to make good career decisions.

$\begin{array}{llllllllll}0 & 1 & 2 & 3 & 4 & 5 & 6 & 7 & 8 & 9\end{array}$

20. Solicit help from an established career person to help chart a course in a given field.

21. Achieve a satisfying career.

22. Market your skills and abilities to others.

23. Identify and evaluate your personal capabilities.

$\begin{array}{llllllllll}0 & 1 & 2 & 3 & 4 & 5 & 6 & 7 & 8 & 9 \\ 0 & 1 & 2 & 3 & 4 & 5 & 6 & 7 & 8 & 9 \\ 0 & 1 & 2 & 3 & 4 & 5 & 6 & 7 & 8 & 9\end{array}$

$\begin{array}{llllllllll}0 & 1 & 2 & 3 & 4 & 5 & 6 & 7 & 8 & 9\end{array}$

24. Find an employer that will provide you with the opportunities you want.

$$
\begin{array}{llllllllll}
0 & 1 & 2 & 3 & 4 & 5 & 6 & 7 & 8 & 9
\end{array}
$$

25. Know how to relate to your boss in order to enhance your career.

$$
\begin{array}{llllllllll}
0 & 1 & 2 & 3 & 4 & 5 & 6 & 7 & 8 & 9
\end{array}
$$

26. Evaluate the job requirements and work environment during a job interview.

$$
\begin{array}{llllllllll}
0 & 1 & 2 & 3 & 4 & 5 & 6 & 7 & 8 & 9 \\
0 & 1 & 2 & 3 & 4 & 5 & 6 & 7 & 8 & 9
\end{array}
$$

27. Prepare for an interview.

28. Select helpful people at the workplace with whom to associate.

$\begin{array}{llllllllll}0 & 1 & 2 & 3 & 4 & 5 & 6 & 7 & 8 & 9\end{array}$

29. Identify your work skills.

$\begin{array}{llllllllll}0 & 1 & 2 & 3 & 4 & 5 & 6 & 7 & 8 & 9\end{array}$


HOW CONFIDENT ARE YOU IN YOUR ABILITY TO:

VERY LITTLE $\quad$ VERY MUCH

30. Organize and carry out your career goals. $\quad \begin{array}{lllllllllll}0 & 1 & 2 & 3 & 4 & 5 & 6 & 7 & 8 & 9\end{array}$

31. Deal effectively with societal barriers. $\quad \begin{array}{lllllllllll}0 & 1 & 2 & 3 & 4 & 5 & 6 & 7 & 8 & 9\end{array}$

32. Research potential career options prior to searching for a job.

$\begin{array}{llllllllll}0 & 1 & 2 & 3 & 4 & 5 & 6 & 7 & 8 & 9\end{array}$

33. Deal effectively with personal barriers. $\quad \begin{array}{lllllllllll}0 & 0 & 1 & 2 & 3 & 4 & 5 & 6 & 7 & 8 & 9\end{array}$

34. Develop effective questions for an $\begin{array}{lllllllllll}\text { information interview. } & 0 & 1 & 2 & 3 & 4 & 5 & 6 & 7 & 8 & 9\end{array}$

35. Understand how your skills can be effectively used in a variety of jobs.

$\begin{array}{llllllllll}0 & 1 & 2 & 3 & 4 & 5 & 6 & 7 & 8 & 9\end{array}$ 


\section{The Hope Scale}

Directions: Please read each item carefully. Using the scale shown below, please select the number that best describes YOU and put that number in the blank provided.

1 = Definitely False $\quad 2$ = Mostly False $\quad 3$ = Mostly True $\quad 4$ = Definitely True

1. I can think of many ways to get out of a jam.

2. I energetically pursue my goals.

3. I feel tired most of the time.

4. There are lots of ways around any problem.

5. I am easily downed in an argument.

6. I can think of many ways to get the things in life that are most important to me.

7. I worry about my health.

8. Even when others get discouraged, I know I can find a way to solve the problem.

9. My past experiences have prepared me well for my future.

10. I've been pretty successful in life.

11. I usually find myself worrying about something.

12. I meet the goals I set for myself. 


\section{REFERENCES}

Albert, K. A., \& Luzzo, D. A. The role of perceived barriers in career development: A social cognitive perspective. Journal of Counseling and Development, 77, $431-436$.

Allen, L. C., MacKenzie, D. L., \& Hickman, L. J. (2001). The effectiveness of cognitive behavioral treatment for adult offenders: A methodological, quality-based review. International Journal of Offender Therapy and Comparative Criminology, 45, 498-514.

Andrews, D. A., Zinger, I., Hoge, R. D., Bonta, J., Gendreau, P., \& Cullen, F. T. (1990). Does correctional treatment work: A clinically relevant and psychologically informed meta-analysis. Criminology, 28, 369-404.

Bandura, A. (1986). Social foundations of thought and action: A social cognitive theory. Englewood Cliffs, NJ: Prentice Hall.

Bandura, A. (1991). Human agency: The rhetoric and reality. American Psychologist, $46,157-162$.

Bloom, D. (2006, July). Employment-focused programs for ex-prisoners: What have we learned, what are we learning, and where should we go from here? Paper presented at the meeting of Research on Prisoner Reentry: What Do We Know and What Do We Want to Know? University of Michigan, Ann Arbor.

Blustein, D. L., McWhirter, E. H., \& Perry, J. C. (2005). An emancipatory communitarian approach to vocational development theory, research, and practice. The Counseling Psychologist, 33, 141-179.

Bourgon, G., \& Armstrong, B. (2005). Transferring the principles of effective treatment in a "real world" prison setting. Criminal Justice and Behavior, 32, 3-25.

Bronfenbrenner, U. (1979). Ecological systems theory. Annals of Child Development, 6, $187-249$. 
Brown, S. D., \& Krane, N. E. (2000). Four (or five) sessions and a cloud of dust: Old assumptions and new observations about career counseling. In S. D. Brown and R. W. Lent (Eds.), Handbook of counseling psychology (3rd ed., pp. 740-766). New York: Wiley.

Bureau of Justice Statistics. (2004). Prison statistics. Washington, DC: U. S. Department of Justice. Retrieved from http://www.ojp.usdoj.gov/bjs/prisons.htm

Bushway, S. D. (1998). The impact of an arrest on the job stability of young white American men. Journal of Research in Crime and Delinquency, 35, 454-479.

Chartrand, J. M., \& Rose, M. L. (1996). Career interventions for at-risk populations: Incorporating social cognitive influences. Career Development Quarterly, 44, 341-353.

Chronister, K. M. (2005). Advancing career counseling and educational support for survivors of domestic violence. Eugene, OR: University of Oregon.

Chronister, K. M., \& McWhirter, E. H. (2003). Applying social cognitive career theory to the empowerment of battered women. Journal of Counseling and Development, $81,418-425$.

Chronister, K. M., \& McWhirter, E. H. (2006). An experimental examination of two career interventions for battered women. Journal of Counseling Psychology, 53, 151-164.

Coppolo, G., Reinhart, C., \& Nelson, J. (2005). Consequences of a felony conviction regarding employment (Office of Legislative Research Rep. No. 2005-R-0311). Hartford, CT: Connecticut General Assembly.

D'Alessio, S. J., \& Stolzenberg, L. (1995). Unemployment and the incarceration of pretrial defendants. American Sociological Review, 60, 350-359.

Diemer, M. A., \& Blustein, D. (2006). Critical consciousness and career development among urban youth. Journal of Vocational Behavior, 68, 220-232.

Englander, F. (1983). Helping ex-offenders enter the labor market. Monthly Labor Review, 106, 25-30.

Filella-Guiu, G., \& Blanch-Plana, A. (2002). Imprisonment and career development: An evaluation of a guidance programme for job finding. Journal of Career Development, 29, 55-68. 
Foster, T. (1999). When will they ever work? Journal of Forensic Psychiatry, 10, 245-248.

Freeman, R. (2003, May). Can we close the revolving door? Recidivism vs. employment of ex-offenders in the U.S. Paper presented at the Urban Institute Re-Entry Roundtable, New York.

Freire, P. (1970). Pedagogy of the oppressed. New York: Continuum.

Gendreau, P. (1995). The principles of effective intervention with offenders. In A. Harland (Ed.), Choosing correctional options that work (pp. 117-130). Thousand Oaks, CA: Sage.

Gendreau, P. (1996). Offender rehabilitation: What we know and what needs to be done. Criminal Justice and Behavior, 23, 144-161.

Grassian, S., \& Friedman, R. (1986). Effects of sensory deprivation in psychiatric seclusion and solitary confinement. International Journal of Law and Psychiatry, 8, 49-54.

Hackett, G., \& Byars, A. M. (1996). Social cognitive theory and the career development of African American women. Career Development Quarterly, 44, 322-340.

Harrison, B., \& Schehr, R. C. (2004). Offenders and post-release jobs: Variables influencing success and failure. Journal of Offender Rehabilitation, 39, 35-68.

Heppner, P. P. (1988). The Problem Solving Inventory manual. Palo Alto, CA: Consulting Psychologists Press.

Heppner, P. P. (2004). Problem-solving appraisal and human adjustment: A review of 20 years of research using the Problem Solving Inventory. Counseling Psychologist, 32(3), 344-428.

Heppner, P. P., Kivlighan, D. M., \& Wampold, B. E. (1999). Research design in counseling (2nd ed.). Pacific Grove, CA: Brooks Cole.

Hodgins, S., \& Cote, G. (1991). The mental health of penitentiary inmates in isolation. Canadian Journal of Criminology, April, 175-182.

Holzer, H. J., Raphael, S., \& Stoll, M. A. (2003, May). Employment barriers facing exoffenders. Paper presented at the Urban Institute Re-Entry Roundtable, New York. 
Inciardi, J. A., Martin, S. S., \& Butzin, C. A. (2004). Five-year outcomes of therapeutic community treatment of drug-involved offenders after release from prison. Crime and Deliquency, 50, 88-107.

Jackson, K. L. (1997). Differences in the background and criminal justice characteristics of young black, white, and Hispanic male federal prison inmates. Journal of Black Studies, 27, 494-509.

Kenny, M. E., Blustein, D. L., Chaves, A., Grossman, J. M., \& Gallagher, L. A. (2000). The role of perceived barriers and relational support in the educational and vocational lives of urban high school students. Journal of Counseling Psychology, 50, 142-155.

Kraus, L. J., \& Hughey, K. F. (1999). The impact of an intervention on career decisionmaking self-efficacy and career indecision. Professional School Counseling, 2, 384-341.

Kupers, T. A. (2005). Toxic masculinity as a barrier to mental health treatment in prison. Journal of Clinical Psychology, 61, 1-12.

Landenberger, N. A., \& Lipzey, M. W. (2005). The positive effects of cognitivebehavioral programs for offenders: A meta-analysis of factors associated with effective treatment. Journal of Experimental Criminology, 1, 451-476.

Lane, J., Lane, A. M., \& Kyprianou, A. (2004). Self-efficacy, self-esteem and their impact on academic performance. Social Behavior and Personality, 32, $247-256$.

Lent, R. W., Brown, S. D., \& Hackett, G. (1994). Monograph: Toward a unifying social cognitive theory of career and academic interest, choice, and performance. Journal of Vocational Behavior, 45, 79-122.

Lent, R. W., Brown, S. D., \& Hackett, G. (2000). Contextual supports and barriers to career choice: A social cognitive analysis. Journal of Counseling Psychology, 47, 36-49.

Leukefeld, C., McDonald, H. S., Staton, M., Mateyoke-Scrivner, A., Webster, M., Logan, T. K., et al. (2003). An employment intervention for drug-abusing offenders. Federal Probation, 67, 27-31. 
Marbley, A. F., \& Ferguson, R. (2005). Responding to prisoner reentry, recidivism, and incarceration of inmates of color: A call to the communities. Journal of Black Studies, 35, 633-649.

McWhirter, E. (1994). Counseling for empowerment. Alexandria, VA: American Counseling Association.

Messina, N., Burdon, W., Hagopian, G., \& Prendergast, M. (2004). One year return to custody rates among co-disordered offenders. Behavioral Sciences and the Law, $22,503-518$.

Morrow, S. L., Gore, P. A., \& Campbell, B. W. (1996). The application of a sociocognitive framework to the career development of lesbian women and gay men. Journal of Vocational Behavior, 48, 136-148.

Petersilia, J. (2001). When prisoners return to the community: Political, economic and social consequences. Federal Probation, 65, 3-8.

Petersilia, J. (2004). What works in prisoner reentry? Reviewing and questioning the evidence. Federal Probation, 68, 2-8.

Platt, J. J. (1995). Vocational rehabilitation of drug abusers. Psychological Bulletin, $117,416-433$.

Pratto, F., Sidanius, J., Stallworth, L. M., \& Malle, B. F. (1994). Social dominance orientation: A personality variable predicting social and political attitudes. Journal of Personality and Social Psychology, 67, 741-763.

Public Safety Performance Project. (2007). Public safety, public spending: Forecasting America's prison population 2007-2011. Washington, DC: Pew Charitable Trust.

Rahill-Beuler, C. M., \& Trait Kretzer, K. M. (1997). Helping offenders find employment. Federal Probation, 61, 35-37.

Re-Entry Policy Council. (2005). The report of the Re-Entry Policy Council: Charting the safe and successful return of prisoners to the community. New York: Council of State Governments.

Ross, R. R., \& Fabiano, E. A. (1980). Time to think: Cognition and crime: Link and remediation. Ottawa, Ontario, Canada: Ministry of the Solicitor General. 
Ross, R. R., Fabiano, E. A., \& Ewles, C. D. (1988). Reasoning and rehabilitation. International Journal of Offender Therapy and Comparative Criminology, 32, 29-35.

Sarason, I. G., Levine, H. M., Basham, R. B., \& Sarason, B. R. (1983). Assessing social support: The Social Support Questionnaire. Journal of Personality and Social Psychology, 44, 127-139.

Seiter, R. P., \& Kadela, K. R. (2003). Prisoner reentry: What works, what does not, and what is promising. Crime and Deliquency, 49, 360-388.

Snyder, C. R., Harris, C., Anderson, J. R., Holleran, S. A., Irving, L. M., Sigmon, S. T. et al. (1991). The will and the ways: Development and validation of an individual differences measure of hope. Journal of Personality and Social Psychology, 60(4), 570-585.

Solberg, V. S., Good, G. E., Fischer, A. R., Brown, S. D., \& Nord, D. (1995). Career decision making, and career search activities: Relative effects of career search self-efficacy and human agency. Journal of Counseling Psychology, 42, $448-455$.

Solberg, V. S., Good, G., \& Nord, D. (1991, August). Career efficacy scale for research and practice. In G. Good \& V. S. Solberg (Co-Chairs), Career self-efficacy: Advances in theory, measurement, and practice. Symposium conducted at the 99th Annual Convention of the American Psychological Association, San Francisco.

Solberg, V. S., Good, G. E., Nord, D., Holm, C., Hohner, R., Zima, N., et al. (1994). Assessing career search expectations: Development and validation of the Career Search Efficacy Scale. Journal of Career Assessment, 2, 11-123.

Swanson, J. L., \& Daniels, K. K. (1996). Assessing perceptions of career-related barriers: The Career Barriers Inventory. Journal of Career Assessment, 4, 219-244.

Uggen, C. (1999). Ex-offenders and the conformist alternative: A job quality model of work and crime. Social Problems, 46, 127-151.

Unwin, T., Mayers, J., \& Wilt, D. (1999, October). Linking offenders and jobs: See the success coming. Corrections Today, 114-132. 
Van Wormer, K. (1999). The strengths perspective: A paradigm for correctional counseling. Federal Probation, 69, 51-58.

Vernick, S. H., \& Reardon, R. C. (2001). Career development programs in corrections. Journal of Career Development, 27, 265-277.

Visher, C. A., Winterfield, L., \& Coggeshall, M. B. (2005). Ex-offender employment programs and recidivism: A meta-analysis. Journal of Experimental Criminology, 1, 295-315.

Walters, G. D. (2005). Recidivism in released lifestyle change program participants. Criminal Justice and Behavior, 32, 50-68.

Wanberg, C. R., Kanfer, R., \& Rotundo, M. (1999). Unemployed individuals: Motives, job-search competencies, and job-search constraints as predictors of job seeking and reemployment. Journal of Applied Psychology, 84, 897-910.

Wilson, D. B., Bouffard, L. A., \& MacKenzie, D. L. (2005). A quantitative review of structured, group-oriented, cognitive-behavioral programs for offenders. Criminal Justice and Behavior, 32, 172-204.

Wolkstein, E., \& Spiller, H. (1998). Providing vocational services to clients in substance abuse rehabilitation. Directions in Rehabilitation Counseling, 9, 65-77.

Zimmerman, M. A., \& Zahniser, J. H. (1991). Refinements of sphere-specific measures of perceived control: Development of a sociopolitical control scale. Journal of Community Psychology, 19, 189-204. 